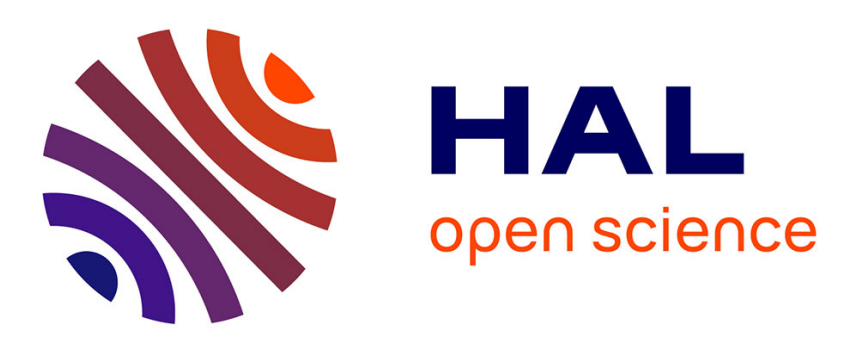

\title{
Forcing of oceanic heat anomalies by air-sea interactions in the Nordic Seas area
}

P. Schlichtholz, Marie-Noëlle Houssais

\section{To cite this version:}

P. Schlichtholz, Marie-Noëlle Houssais. Forcing of oceanic heat anomalies by air-sea interactions in the Nordic Seas area. Journal of Geophysical Research, 2011, 116, pp.01006. 10.1029/2009JC005944 . hal-00755400

\author{
HAL Id: hal-00755400 \\ https://hal.science/hal-00755400
}

Submitted on 4 Nov 2021

HAL is a multi-disciplinary open access archive for the deposit and dissemination of scientific research documents, whether they are published or not. The documents may come from teaching and research institutions in France or abroad, or from public or private research centers.
L'archive ouverte pluridisciplinaire HAL, est destinée au dépôt et à la diffusion de documents scientifiques de niveau recherche, publiés ou non, émanant des établissements d'enseignement et de recherche français ou étrangers, des laboratoires publics ou privés.

$$
\text { Copyright }
$$




\title{
Forcing of oceanic heat anomalies by air-sea interactions in the Nordic Seas area
}

\author{
P. Schlichtholz ${ }^{1}$ and M.-N. Houssais ${ }^{2}$ \\ Received 28 October 2009; revised 14 September 2010; accepted 19 October 2010; published 15 January 2011.
}

[1] Hydrographic data and atmospheric reanalysis from 1982 to 2005 are used to show a strong link of the Atlantic water temperature (AWT) anomalies observed in the transition zone between the Norwegian Atlantic current and the West Spitsbergen current in summer to the surface heat flux (SHF) anomalies observed over the Barents Sea open water in the preceding late winter. A mechanism proposed for this link is formation of ocean temperature anomalies in a deep mixed layer and their subsequent westward export by a branch of Atlantic water recirculating in the western Barents Sea. The SHF anomalies over the Barents Sea are due to advection of temperature and humidity by anomalous winds across the Arctic ice edge and do not strongly depend on the North Atlantic oscillation (NAO). Correlations of up to about 0.9 between the AWT anomalies and indices of atmospheric variability over the Barents Sea open prospects for seasonal AWT predictability. It is also shown that the wind-forcing responsible for positive AWT anomalies is involved in a cyclonic perturbation of the atmospheric circulation over the Nordic Seas. This perturbation generates, through influence on the sea ice distribution, a lobe of SHF anomalies in the marginal ice zone (MIZ) on the eastern (Barents Sea) and western (Greenland Sea) sides of the Nordic Seas which has the opposite sign to the open water lobe. In contrast to the Barents Sea MIZ, the diabatic heating of the atmosphere by upward SHF anomalies in the Greenland Sea MIZ competes with cold advection.

Citation: Schlichtholz, P., and M.-N. Houssais (2011), Forcing of oceanic heat anomalies by air-sea interactions in the Nordic Seas area, J. Geophys. Res., 116, C01006, doi:10.1029/2009JC005944.

\section{Introduction}

[2] The upper limb of the thermohaline and winddriven North Atlantic circulation conveys warm and salty Atlantic water to the Nordic (Greenland-Iceland-Norwegian and Barents) Seas (Figure 1). After crossing the GreenlandScotland ridge, the Atlantic water flows northward on the eastern side of the Nordic Seas, in the Norwegian Atlantic current (NwAC in Figure 1a). The current splits northwest of Norway into two branches heading the Arctic Ocean. One branch, the West Spitsbergen current (WSC in Figure 1a), streams northward along the shelf slope [Schauer et al., 2004], whereas the other branch, the North Cape current ( $\mathrm{NCaC}$ in Figure 1a), crosses the Barents Sea shelf [Ingvaldsen et al., 2004]. A western branch of the Norwegian Atlantic current flows northward along the Arctic Front [Orvik and Niiler, 2002] and extends to Fram strait, where it mainly feeds the return Atlantic current (RAC in Figure 1a), which recirculates some Atlantic water southward [Schlichtholz and Houssais, 1999]. The recirculated Atlantic water contributes to the sinking branch of the Atlantic meridional overturning circulation via a direct throughflow to Denmark

\footnotetext{
${ }^{1}$ Institute of Oceanology, Polish Academy of Sciences, Sopot, Poland. ${ }^{2}$ LOCEAN, UMR 7159, CNRS/UPMC/IRD/MNHN, Paris, France.
}

Copyright 2011 by the American Geophysical Union. 0148-0227/11/2009JC005944 strait [Mauritzen, 1996] or through preconditioning of dense water formation in the Greenland gyre [Gascard et al., 2002].

[3] Much heat is lost by the Atlantic water on its transit through the Nordic Seas, as suggested by subsurface temperature gradients and sea ice distribution (Figure 1b). Mean winter surface heat flux (SHF) over the West Spitsbergen current and Barents Sea is locally as large as $\sim 300 \mathrm{~W} \mathrm{~m}^{-2}$ [Furevik and Nilsen, 2005], but Atlantic water does not completely lose its warm identity. Although the branch across the Barents Sea is cooled to temperatures below $1{ }^{\circ} \mathrm{C}$ before it enters the Arctic Ocean [Schauer et al., 2002], the layer with temperatures above $1^{\circ} \mathrm{C}$ is $\sim 500 \mathrm{~m}$ thick in the West Spitsbergen current. From a mean northward heat transport of $\sim 300 \mathrm{TW}\left(\mathrm{TW}=10^{12} \mathrm{~W}\right)$ by the Atlantic water across the Greenland-Scotland ridge [Østerhus et al., 2005], 25-50 TW continues into the Arctic Ocean through Fram strait [Schauer et al., 2008].

[4] A number of studies have shown that Atlantic water temperature (AWT) in the West Spitsbergen current is subject to substantial variations. For instance, a 30 year long time series of 50-500 m depth averaged temperatures near Sørkapp (the south cape of Spitsbergen) revealed a $1{ }^{\circ} \mathrm{C}$ warming between the late 1960s and mid-1990s [Blindheim et al., 2000]. A century-long temperature record from the Russian Kola section of the east-central Barents Sea [Skagseth et al., 2008] and an equally long time series of the average temperature of the Atlantic layer in the Arctic Ocean [Polyakov 

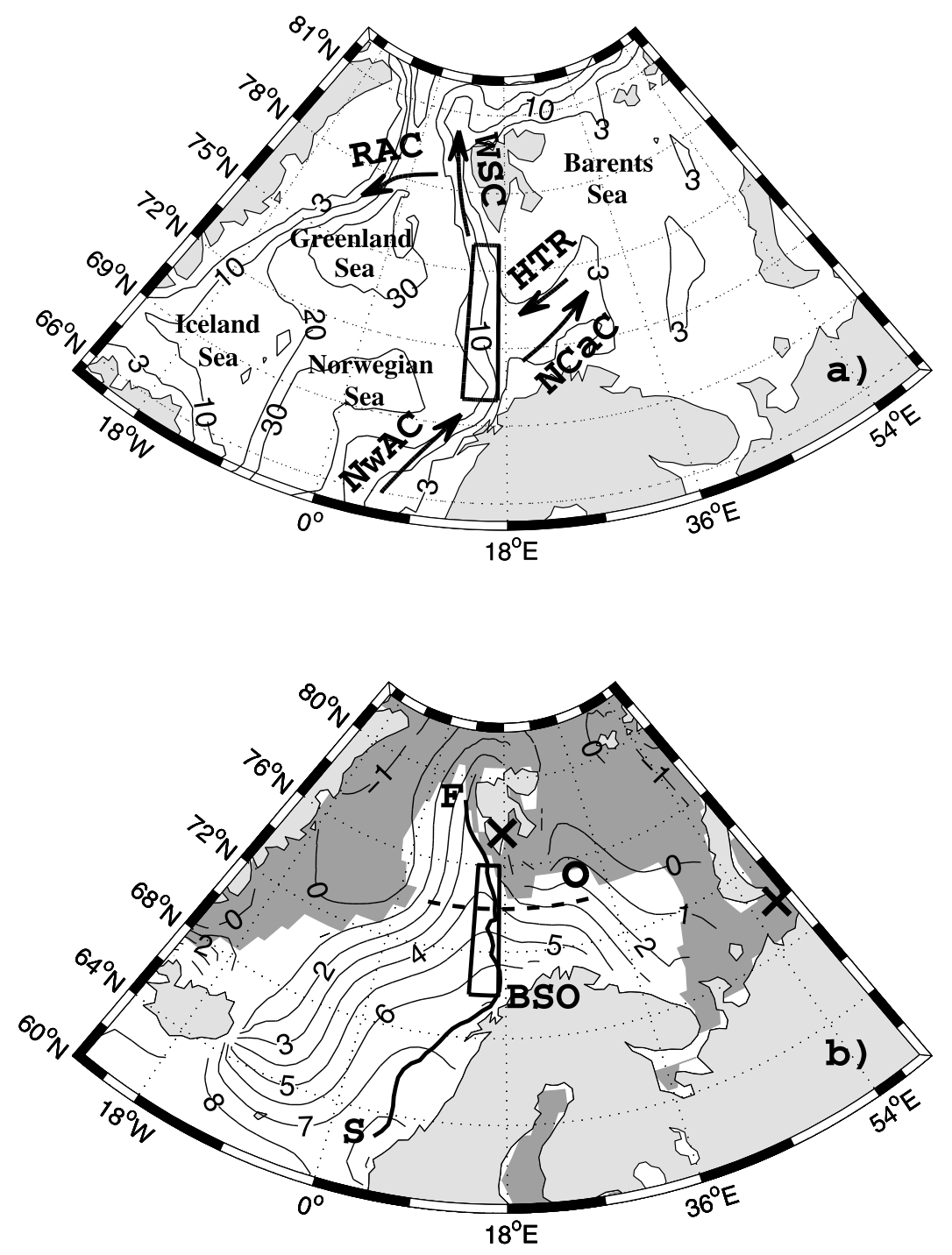

Figure 1. (a) Bathymetry (in $10^{2} \mathrm{~m}$ contours) and (b) annual mean ocean temperature (in degrees Celsius contours) at the depth of $100 \mathrm{~m}$ from a hydrographic climatology [Steele et al., 2001] in the Nordic Seas area. In Figure 1a, the 300,1000, 2000, and $3000 \mathrm{~m}$ isobaths are plotted while the arrows depict major pathways of Atlantic water through the Nordic Seas: the Norwegian Atlantic current (NwAC), North Cape current $(\mathrm{NCaC})$, West Spitsbergen current (WSC), return Atlantic current (RAC), and Hopen trench recirculation (HTR). In Figures 1a and 1b, the box delineates the Barents Sea Opening (BSO) area. In Figure 1b, dark shading denotes an area where the long-term (1982-2005) mean of the late winter (January-April) sea ice concentration is above 5\%, the circle indicates the Hopen trench area, and the crosses show points for calculation of the OIW index (see Table 1 for definition). In Figure 1b, the thick solid line between the points $\mathrm{S}$ and $\mathrm{F}$ along the $500 \mathrm{~m}$ isobath and the thick dashed line along the $74^{\circ} \mathrm{N}$ parallel show sections for a composite analysis (see Figure 3).

et al., 2004] show that this trend is a part of a large-scale multidecadal climate oscillation. This oscillation strongly affects Arctic sea ice conditions and atmospheric temperature and is linked to hydrographic variability in the North Atlantic [Polyakov et al., 2005a]. The late 20th-century warming in the Arctic was associated with a change in activity of the North Atlantic oscillation (NAO) from its extreme low index phase to its extreme high index phase [e.g., Dickson et al., 2000], but understanding of the multidecadal Arctic climate variability is not trivial, as a similar warming in the early 20th century was apparently not linked to the NAO [Bengtsson et al., 2004].
[5] In the Nordic Seas, strong interannual variability is superimposed on the multidecadal AWT trends. For instance, 16 year long temperature records from five standard Norwegian hydrographic sections, which cover the area from the zone of the Atlantic water inflow between Scotland and Faroe Islands to the West Spitsbergen current at the Sørkapp latitude exhibited a cooling between warm events observed at the beginning of the 1980s and 1990s [Furevik, 2001]. These events, characterized by AWT anomalies on the order of $1{ }^{\circ} \mathrm{C}$, were identified on a section surveyed only once a year, in summer, as well as on sections surveyed several times each year. Substantial AWT anomalies also occurred in 
the period from the mid-1990s to the mid-2000s, as shown by data from the Norwegian sections [Skagseth et al., 2008] as well as from summer cruises of R/V Oceania in the Barents Sea opening (BSO) area (Figure 1, box) [Schlichtholz and Goszczko, 2005] and farther north in the West Spitsbergen current [Walczowski and Piechura, 2006]. Since the AWT anomalies observed in this area propagate into and around the Arctic Ocean [Karcher et al., 2003; Polyakov et al., 2005b] or recirculate with the return Atlantic current [Dickson et al., 1999], they may have a profound impact on the polar and subpolar climate variability.

[6] Similarly to the multidecadal trends, the interannual AWT anomalies in the Nordic Seas are often attributed to the NAO [e.g., Furevik, 2001; Saloranta and Haugan, 2001; Schlichtholz and Goszczko, 2006]. However, their actual physical origin is unclear. Model simulations suggest that they are associated with changes in the heat transport due to variability in the volume flux across the GreenlandScotland ridge [Karcher et al., 2003; Nilsen et al., 2003]. The heat transport from the North Atlantic may also vary because of temperature changes controlled by the dynamics of the subpolar gyre [Hátún et al., 2005], the latter showing some link to the NAO [Herbaut and Houssais, 2009]. Whatever their actual origin, the AWT anomalies observed in the southern Norwegian Sea propagate northward and arrive to the Barents Sea and Fram strait after $\sim 2$ years [Skagseth et al., 2008]. However, some of the observed anomalies amplify in the presumed northward direction of their propagation while other appear simultaneously in the southern and northern part of the Nordic Seas [Furevik, 2001]. This indicates that either variability of the internal circulation in the Nordic Seas or forcing by anomalous local air-sea heat exchanges play a role. The AWT anomalies indeed appear to be modified through regional advection anomalies linked to variations in the path (or transport) of the Norwegian Atlantic current [Orvik and Skagseth, 2005] or through anomalous air-sea interactions over the Norwegian Sea [Nilsen and Falck, 2006]. Air-sea interactions may also act to damp the anomalies before entering the Arctic Ocean in both Fram strait and Barents Sea [Karcher et al., 2003].

[7] Here we focus on the link between the interannual AWT variability and air-sea interactions over the Nordic Seas. The link is investigated using summer subsurface temperature profiles in the BSO box (Figure 1) from oceanic databases together with surface, year-round oceanic and atmospheric gridded fields from 1982 to 2005 . The BSO area is chosen since it is a transition zone in which the Atlantic water core streaming northward along the shelf slope can interact with the circulation in the Barents Sea. The northward flow in the BSO area not only diverges to the east but also converges with the Hopen trench recirculation (HTR in Figure 1a) which recirculates water from a northern limb of the North Cape current [Gawarkiewicz and Plueddemann, 1995]. The question is whether this transition zone acts as a passive northward conveyor of signals coming from the Norwegian Sea or has rather its own dynamics. To minimize aliasing from eddies, estimates of summer mean AWT are used rather than temperature data from snapshot sections. The summer season is chosen since most of available hydrographic data are from that season and also because subsurface water mass properties are not altered by concomitant air-sea interactions in that season [Nilsen and Falck, 2006]. Summer temperature records contain information on atmospheric forcing during the previous cold season and, when compared to the spatial distribution of this forcing, may indicate which of the adjacent areas play a key role in shaping the AWT variability in the area under study. The period 1982-2005 is selected because a quite large number of hydrographic data could be collected for each summer in that period and also because we will relate the summer AWT variability to the presummer evolution of sea-surface temperature (SST) anomalies estimated from a data set based on high-quality satellite and in situ observations which is available from December 1981 onward [Reynolds et al., 2002].

[8] We will show that the AWT anomalies observed in the BSO area can to a large extent be generated by air-sea interactions over the Barents Sea, in particular at the ice edge in the Hopen trench area (Figure 1b, circle). It will be found that these anomalies are only moderately linked to the previous winter NAO and that this link may reflect an impact of the NAO on the Greenland Sea marginal ice zone (MIZ). We will also show that, despite a strong relation of the atmospheric variability in the Hopen trench area to the variability of the Greenland Sea MIZ, the anomalies of the surface atmospheric temperature (SAT) play a different role in the two areas. While they are mainly responsible for the air-sea heat flux variability in the Hopen trench area, they occur as a passive response to the sea ice cover anomalies in the Greenland Sea MIZ.

[9] The study is organized as follows. Data and methods are described in section 2. The section starts with construction of the AWT series and selection of "BSO warm summers" and "BSO cold summers" for a composite analysis (section 2.1). Then, selection of surface fields is made (section 2.2) and suitable indices of regional climate variability are defined (section 2.3). Methods used to calculate correlations between the indices and surface fields are described in Appendix A. Basic results are presented and discussed in sections 3 and 4. Section 3 includes an analysis of summer AWT variability (section 3.1), of its links to presummer SHF anomalies (section 3.2), of the particular role of air-sea interactions in the Barents Sea open water (section 3.3), of the link to the atmospheric circulation over the Nordic Seas (section 3.4), and of the relation to the NAO (section 3.5). In section 4, mechanisms responsible for the link of AWT anomalies to the atmospheric variability over the Barents Sea open water are elucidated based on the heat budget of the ocean surface mixed layer (section 4.1) and the surface atmospheric heat balance (section 4.2). The contrasted response of the eastern and western MIZs of the Nordic Seas is finally investigated in section 5, where first late winter anomalies are analyzed (section 5.1) and then the presummer evolution of anomalies is discussed (section 5.2). A summary and conclusions follow in section 6 .

\section{Data and Methods}

\subsection{Atlantic Water Temperature}

[10] A time series of summer (June-September) mean AWT in the BSO box $\left(13-17^{\circ} \mathrm{E}, 70-76^{\circ} \mathrm{N}\right.$, Figure 1) is constructed using quality-controlled temperature records. As explained in the introduction, the box is in the transition zone between the Norwegian Atlantic current and the West Spitsbergen current where interactions with the Barents Sea 

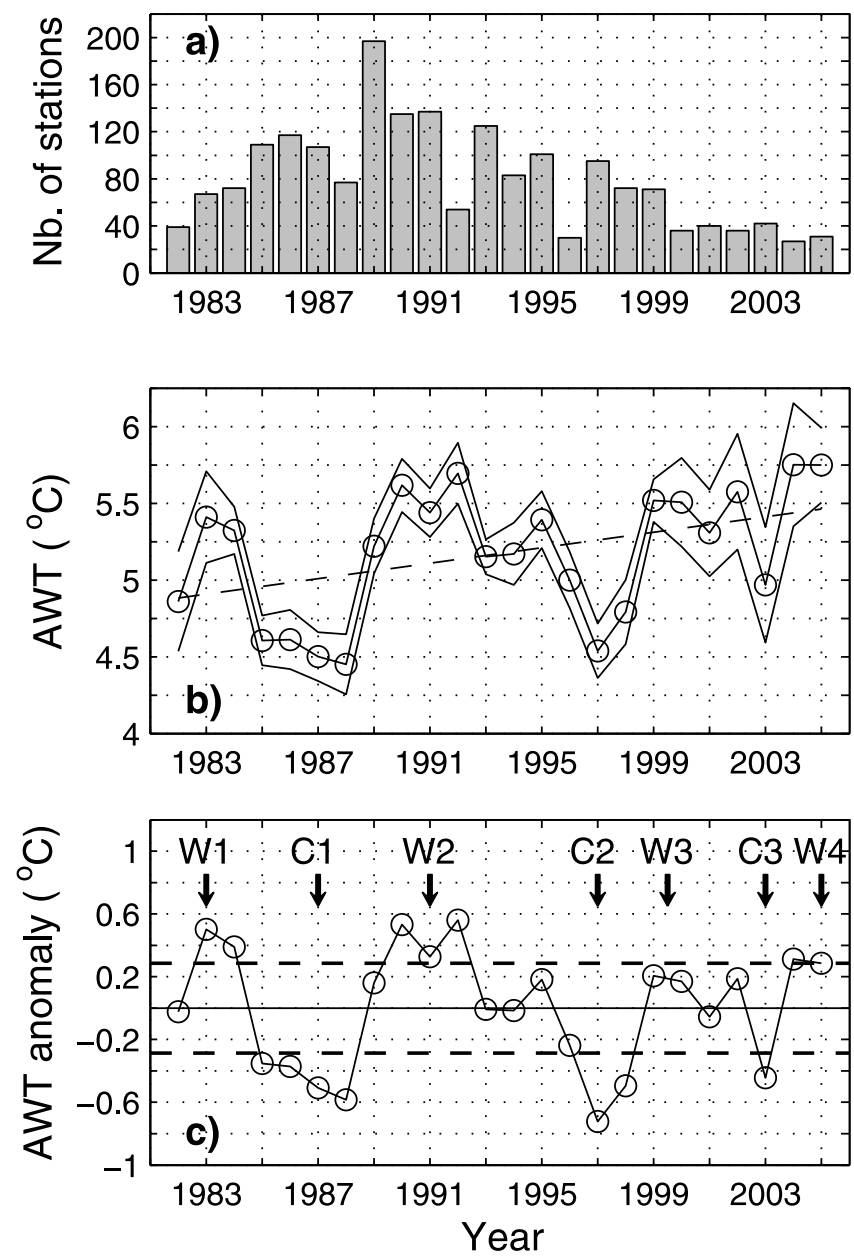

Figure 2. (a) Histogram of hydrographic stations used to construct the time series of (b) summer (June-September) Atlantic water temperature (AWT) averaged over the 100 $300 \mathrm{~m}$ layer in the BSO area (Figure 1, box) and (c) its anomaly from 1982 to 2005. In Figure 2b, the circles, dashed line, and solid unmarked lines denote the AWT series itself, its linear trend, and the $95 \%$ confidence intervals, respectively. In Figure 2c, the anomalies are detrended and \pm 0.75 of their standard deviation (used as a limit for selection of summers in a composite analysis, see Figure 3 ) is marked by dashed horizontal lines while $\mathrm{W} 1, \mathrm{C} 1, \mathrm{~W} 2, \mathrm{C} 2, \mathrm{~W} 3, \mathrm{C} 3$, and W4 indicate warm and cold events discussed in the text.

circulation can occur. The lateral extent of the box is limited to the range of longitudes roughly covering the shelf slope area and corresponding to typical locations of the AWT maximum in the east-west direction. The temperature records are from the Oceanographic Database of the International Council for the Exploration of the Sea (ICES) [International Council for the Exploration of the Sea, 2006] and the World Ocean Database 2005 (WOD05) compiled by the U.S. National Oceanic and Atmospheric Administration (NOAA) [Boyer et al., 2006]. Only data from the Atlantic water core (100-300 m layer) are used. Stations in water shallower than $300 \mathrm{~m}$ or not spanning the entire 100-300 m layer are disregarded. The ICES database provides in all 1713 selected stations, some in each year of the period under study (19822005). The WOD05 database provides 592 stations before
1998 and none afterward. The two data sets are assembled, but the WOD05 stations are included only if differing (location and day of measurements) from the ICES stations. The final set (1900 vertical profiles) consists of stations from inside the BSO box plus two additional stations per year, with one at (or the closest to) the southern and northern limits of the box. The set has a very irregular time distribution but includes at least 27 stations in each year (Figure 2a).

[11] Sampling errors caused by an inhomogeneous distribution of the hydrographic stations may contaminate results of horizontal averaging because of a large northward temperature decrease in the BSO area (Figure 1b). To tackle this problem, all stations are assumed to be on a same meridian and the vertically averaged temperature data in each year are interpolated between the southern and northern limits of the BSO box before taking the meridional average. To obtain reliable AWT estimates with error bars, a Monte Carlo simulation is applied. The interpolation and averaging procedure is repeated 500 times using a randomly selected subset $(50 \%)$ of stations in each year. The mean values of the calculated averages constitute the final AWT time series (Figure $2 b$, circles). The standard deviations of these averages multiplied by the $95 \%$ confidence level for the normal distribution are used as estimates of uncertainty, and determine the confidence intervals for the AWT estimates (Figure 2b, solid unmarked lines). To focus on the interannual variability, AWT anomalies (Figure 2c) are obtained by removing the linear trend (Figure 2b, dashed line) from the basic AWT series. The whole procedure of temperature averaging and calculation of anomalies is then repeated for the upper $(100$ $200 \mathrm{~m})$ and lower $(200-300 \mathrm{~m})$ parts of the Atlantic water core and for the southern $\left(70-73^{\circ} \mathrm{N}\right)$ and northern $\left(73-76^{\circ} \mathrm{N}\right)$ parts of the BSO box.

[12] Composite fields of summer temperatures from the ICES and WOD05 databases are also constructed to investigate the spatial coherence of the subsurface temperature anomalies in the eastern Nordic Seas (Figure 3). First, we select an epoch $W_{0}$ of seven "BSO warm summers" and an epoch $C_{0}$ of seven "BSO cold summers" based on the time series of the AWT anomalies in the BSO area (Figure 2c, circles). The warm (respectively, cold) epoch includes the summers of 1983, 1984, 1990, 1991, 1992, 2004, and 2005 (respectively, the summers of 1985, 1986, 1987, 1988, 1997, 1998, and 2003) for which the AWT anomaly is greater than 0.75 (respectively, smaller than -0.75 ) of the standard deviation of all AWT anomalies in the 1982-2005 period (Figure 2c, dashed horizontal lines). Composite mean temperatures in the 100-300 m layer for these epochs are then constructed along the $500-\mathrm{m}$ isobath in the eastern shelf slope region of the Nordic Seas (Figure 1b, thick solid line) from $\sim 63^{\circ} \mathrm{N}$ (point $\mathrm{S}$ collocated with the shallowest mooring of the Svinøy array in the southern Norwegian Sea) [e.g., Skagseth et al., 2008] to $\sim 79^{\circ} \mathrm{N}$ (point F in the area of moorings in Fram strait) [e.g., Schauer et al., 2008]. Layeraveraged temperatures at a resolution of $50 \mathrm{~km}$ are calculated using, for a given point, hydrographic stations located within a $100-\mathrm{km}$ radius between the 300 and $700 \mathrm{~m}$ isobaths. The difference in the composite temperature between the $W_{0}$ and $C_{0}$ epochs is then obtained at points for which data from at least 5 stations contribute to the composites (typically $\sim 40$ stations, median value). The significance of the difference is tested using a $t$ statistic with the number of 

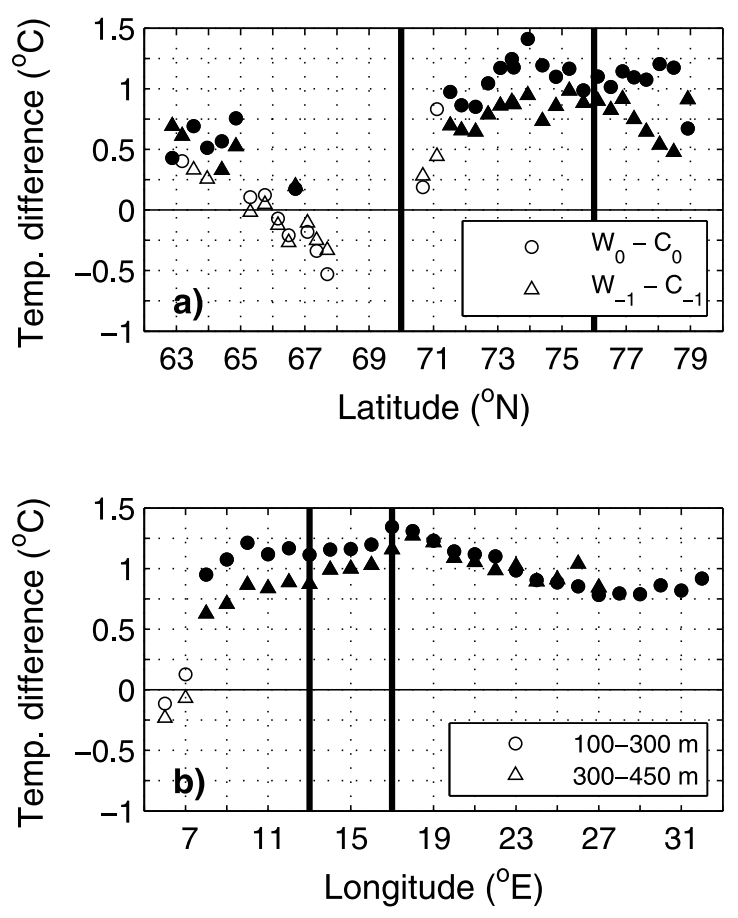

Figure 3. (a) Difference in the composite mean of the average temperature in the 100-300 m layer between the "BSO warm summers" and the "BSO cold summers" (circles) and between the summers 1 year before the "BSO warm summers" and "BSO cold summers" (triangles) along the 500-m isobath from point $\mathrm{S}$ to point $\mathrm{F}$ in Figure $1 \mathrm{~b}$. (b) Difference in the composite mean of the average temperature in the 100 $300 \mathrm{~m}$ (circles) and 300-450 $\mathrm{m}$ (triangles) layers between the "BSO warm summers" and the "BSO cold summers" along a zonal section at $74^{\circ} \mathrm{N}$ (thick dashed line in Figure 1b). See the dashed horizontal lines in Figure 2c for the threshold values used in the selection of the warm and cold summers and the text for details of construction of the composites. In Figures $3 \mathrm{a}$ and $3 \mathrm{~b}$, the temperature differences are shown only at the points where the composite means are based on data from at least five hydrographic stations. The filled symbols indicate that the differences are statistically significant at the $95 \%$ confidence level and the bold vertical lines show the limits of the BSO area.

degrees of freedom determined from the temperature variances in both epochs [von Storch and Zwiers, 1999, p. 113]. To address the problem of the propagation of anomalies along the shelf slope, we repeat a similar composite analysis for the summers preceding by 1 year the $W_{0}$ and $C_{0}$ summers, that is, the epoch $W_{-1}$ (summers of 1982, 1983, 1989, 1990, 1991, 2003, and 2004) and the epoch $C_{-1}$ (summers of 1984, 1985, 1986, 1987, 1996, 1997, and 2002). Similarly, a composite analysis of the temperature in the $100-300 \mathrm{~m}$ layer and in the 300-450 m layer is carried out for the $W_{0}$ and $C_{0}$ epochs along the $\left(74^{\circ} \mathrm{N}\right)$ parallel corresponding approximately to the latitude of extreme mean westward outflow from the Barents Sea [e.g., Skagseth, 2008]. The composites are calculated from $6^{\circ} \mathrm{E}$ to $32^{\circ} \mathrm{E}$ (Figure $1 \mathrm{~b}$, thick dashed line) with a resolution of $1^{\circ}$ longitude using for a given point the layer-averaged temperature data from all hydrographic stations within a $100 \mathrm{~km}$ radius.

\subsection{Surface Fields}

[13] Links of AWT variability to surface processes in the Nordic Seas area are studied using records of SST, sea ice concentration (SIC) and various atmospheric fields. We use monthly mean fields (http://www.cdc.noaa.gov/) of SST/ SIC on a $1^{\circ}$ lat $\times 1^{\circ}$ long grid compiled by NOAA [Reynolds et al., 2002]. The atmospheric data (http://www.cdc.noaa. gov/) are from the U.S. National Centers for Environmental Prediction/National Center for Atmospheric Research (NCEP/ NCAR) reanalysis [Kalnay et al., 1996]. In the present analysis, monthly or daily mean fields from 1982 to 2005 are used. The monthly mean fields include the sensible, latent, net shortwave radiative, and net longwave radiative contributions to the total SHF, the sea level pressure (SLP), and the two components of the surface wind stress (see also Table 1 for acronyms and symbols). Positive values correspond to a downward heat flux. The SLP is on a $2.5^{\circ}$ lat $\times$ $2.5^{\circ}$ long grid while all other variables (monthly and daily) are on the T62 reanalysis grid (ca. $2^{\circ}$ lat $\times 2^{\circ}$ long). The daily mean fields include the $2 \mathrm{~m}$ height air temperature (SAT), the $2 \mathrm{~m}$ height specific humidity (SHUM), and the two components of the surface (10 m height) wind velocity from which the surface wind speed is calculated.

[14] To focus on the seasonal timescale, all monthly and daily mean fields are averaged over 4 months with the interval of 1 month. The basic (overlapping) seasons complementing the summer (June-September) season are autumn (SeptemberDecember), winter (December-March), and spring (MarchJune). The seasons starting 1 month earlier and later than the basic seasons are referred to as "early" and "late," respectively, for example, early (late) winter for the NovemberFebruary (January-April) season, and so on.

Table 1. Correlation $r$ of the Summer AWT Anomalies in the BSO Area in the 1982-2005 Period (Figure 2c) With Some Indices of Presummer Variability in the Nordic Seas Area ${ }^{a}$

\begin{tabular}{|c|c|c|c|c|c|c|}
\hline Variable & Acronym & Symbol & $\mathrm{Lag}^{\mathrm{b}}$ & $r$ & $p \times 100$ & $N_{\text {eff }}$ \\
\hline Sea ice concentration ${ }^{c}$ & SIC & 一 & -2 & -0.87 & 0.01 & 11.2 \\
\hline $\begin{array}{l}\text { Sea surface } \\
\text { temperature }^{\mathrm{d}}\end{array}$ & SST & $T_{o}$ & -3 & 0.91 & 0.02 & 8.3 \\
\hline Surface heat flux ${ }^{\mathrm{d}}$ & $\mathrm{SHF}^{\mathrm{e}}$ & $Q$ & -5 & 0.86 & 0.02 & 10.7 \\
\hline $\begin{array}{l}\text { Surface air } \\
\text { temperature }^{\mathrm{f}}\end{array}$ & SAT & $T_{a}$ & -5 & 0.87 & 0.05 & 8.9 \\
\hline $\begin{array}{l}\text { Surface specific } \\
\text { humidity }\end{array}$ & SHUM & - & -5 & 0.92 & 0.01 & 8.6 \\
\hline $\begin{array}{l}\text { Atmospheric heat } \\
\text { advection }^{\mathrm{d}}\end{array}$ & - & $A$ & -5 & 0.83 & 0.04 & 11.3 \\
\hline Ekman suction $^{\mathrm{d}}$ & - & $w_{E}$ & -5 & 0.78 & 0.13 & 11.6 \\
\hline $\begin{array}{l}\text { "On Ice Wind" } \\
\text { index }{ }^{\mathrm{g}}\end{array}$ & OIW & - & -5 & 0.84 & 0.05 & 10.6 \\
\hline $\begin{array}{l}\text { North Atlantic } \\
\text { Oscillation }^{\text {h }}\end{array}$ & NAO & - & -6 & 0.56 & 1.80 & 15.4 \\
\hline
\end{tabular}

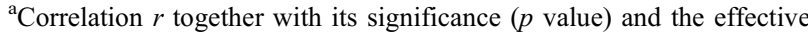
number of degrees of freedom $\left(N_{\text {eff }}\right)$. All time series are detrended.

${ }^{\mathrm{b}}$ In months (all indices are based on 4 month mean values).

${ }^{\mathrm{c}}$ Local in the Barents Sea marginal ice zone (MIZ).

${ }^{\mathrm{d}}$ At the ice edge in the Hopen trench area (circle in Figure 1b).

${ }^{\mathrm{e}}$ Positive downward.

${ }^{f}$ Averaged over the Barents Sea open water.

${ }^{\mathrm{g}}$ Normalized sea level pressure (SLP) difference between the southern tips of Novaya Zemlya and Spitsbergen (crosses in Figure 1b).

${ }^{\mathrm{h}} \mathrm{SLP}$ difference between Lisbon and Stykkisholmur. 

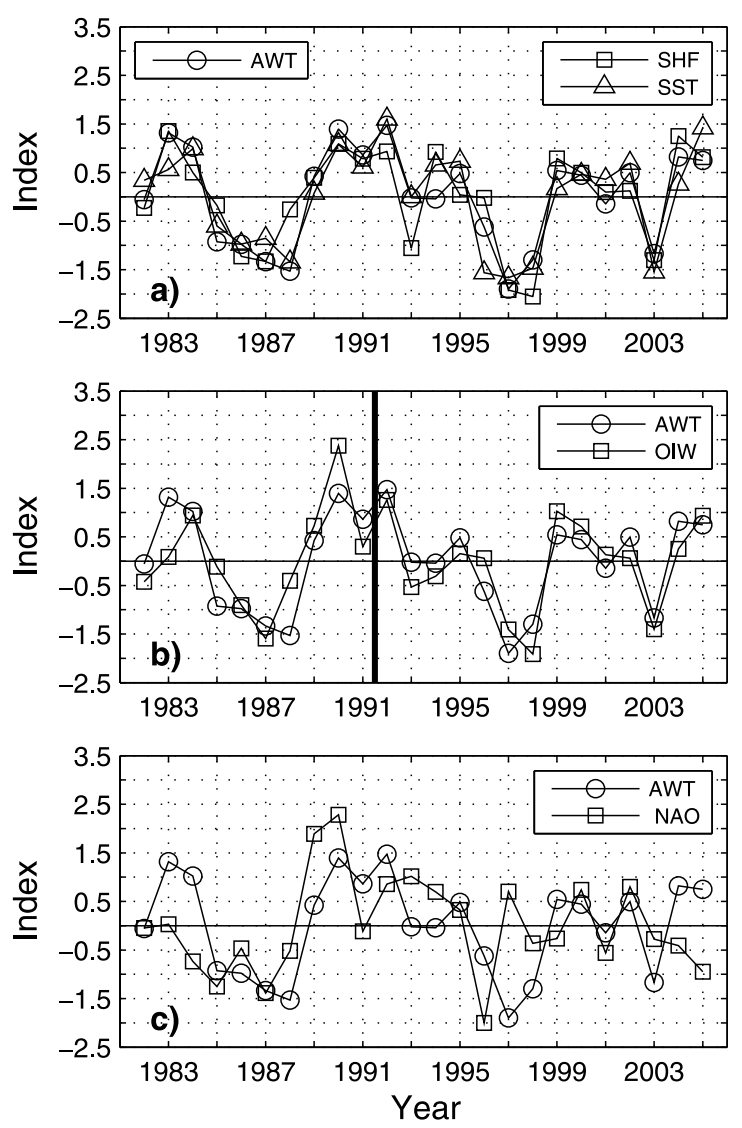

Figure 4. Comparison of the summer AWT index (circles), defined as the ratio between the anomalies from Figure $2 \mathrm{c}$ and their standard deviation, with (a) the detrended and normalized anomalies of the late winter total SHF (squares, positive downward) and spring SST (triangles) in the Hopen trench area (at the circle in Figure 1b), (b) the late winter OIW index (squares, see Table 1 for definition), and (c) the late winter pattern-based NAO index (squares) obtained from the detrended SLP anomalies in the North Atlantic sector $\left(90^{\circ} \mathrm{W}-40^{\circ} \mathrm{E}, 20-70^{\circ} \mathrm{N}\right)$ in the $1982-2005$ period. In Figure $4 \mathrm{~b}$, the bold vertical line separates the "training" period from the "validation" period of a simple statistical prediction model (see Figure 16).

[15] To investigate the surface atmospheric heat balance, contributions from temperature advection by the seasonal mean winds $(A)$ and the eddy heat flux convergence due to the subseasonal variability $(E)$ are estimated from the following formulae:

$$
A=-\overline{\overline{\mathbf{u}}}_{a} \cdot \nabla \overline{\bar{T}}_{a}
$$

and

$$
E=-\nabla \cdot \overline{\overline{\mathbf{u}_{a}^{\prime \prime} T_{a}^{\prime \prime}}}
$$

where $\mathbf{u}_{a}$ and $T_{a}$ are the surface wind velocity and the SAT, respectively, $\nabla$ is the horizontal gradient operator while the double overbar and double prime indicate seasonal averaging and daily anomaly with respect to the seasonal average, respectively. Analogous terms to $A$ and $E$ are also calculated for SHUM instead of SAT. Hereafter only seasonal mean variables will be considered and the double overbar will be dropped for the sake of clarity.

[16] To study the effects of the wind-driven oceanic circulation on the Ekman layer temperature (assumed equal to the SST), the surface Ekman transport $\left(\mathbf{U}_{E}\right)$ is calculated from the relation

$$
\mathbf{U}_{E}=\frac{\boldsymbol{\tau}_{s} \times \mathbf{k}}{f \rho_{w}},
$$

where $\tau_{s}$ is the surface wind stress, $\mathbf{k}$ is a vertical unit vector, $f$ is the Coriolis parameter, and $\rho_{w}$ is the density of seawater (assumed equal to $1027 \mathrm{~kg} \mathrm{~m}^{-3}$ ). $\mathbf{U}_{E}$ is then used to obtain the Ekman suction velocity $\left(w_{E}=\boldsymbol{\nabla} \cdot \mathbf{U}_{E}\right)$ and heating (in watts per unit area) due to temperature advection by the Ekman flow,

$$
H_{E}=-\rho_{w} c_{w} \mathbf{U}_{E} \cdot \nabla T_{o},
$$

where $T_{o}$ is the SST and $c_{w}$ is the specific heat at constant pressure for seawater (assumed equal to $4000 \mathrm{~J} \mathrm{~kg}^{-1}{ }^{\circ} \mathrm{C}^{-1}$ ).

\subsection{Indices of Variability}

[17] An index of summer AWT variability in the BSO area is obtained by dividing the detrended AWT anomalies from Figure $2 \mathrm{c}$ by their standard deviation (Figure 4, circles). To link the AWT variability to the surface fields, the latter are decomposed into the seasonally varying long-term mean (i.e., a climatological annual cycle denoted by a single overbar) and the departure (anomaly) from this mean (denoted by a single prime), which for, for example, the total SHF, $Q$, writes as

$$
Q=\bar{Q}+Q^{\prime}
$$

For each season, the anomalies are then detrended. Linear regressions onto the AWT index and corresponding correlations $(r)$ are then calculated in which negative lags correspond to the surface fields leading the AWT anomalies. For instance, lags from -7 to -5 months refer to, respectively, the early winter, winter, and late winter preceding a given summer, and so on. The statistical significance of the correlations ( $p$ value) is obtained from a test carried out with an effective number of degrees of freedom (see Appendix A). Correlations statistically significant at the $95 \%$ confidence level $(p<0.05)$ are indicated by shading in the regression maps and by filling of symbols on the regression curves. In the case of the vector quantities $\left(\mathbf{u}_{a}^{\prime}\right.$ and $\left.\mathbf{U}_{E}^{\prime}\right)$, their zonal and meridional components are regressed separately and areas where either of the components are significant are shaded in the regression maps.

[18] Based on the regression analysis, key areas of surface field variability are identified in which additional indices of air-sea interactions are constructed. Indices are shown at a point at the ice edge in the Hopen trench area (Figure 1b, circle) characterized by the strongest AWT-associated late winter downward anomaly of SHF (Figure 5a, circle). The presummer evolution of the regression coefficients or correlations is analyzed at this point, at two other points in the open water, one in the Norwegian Sea (Figure 5a, upsidedown triangle), and one in the BSO area (Figure 5a, square) and also at two points located in areas of the strongest 

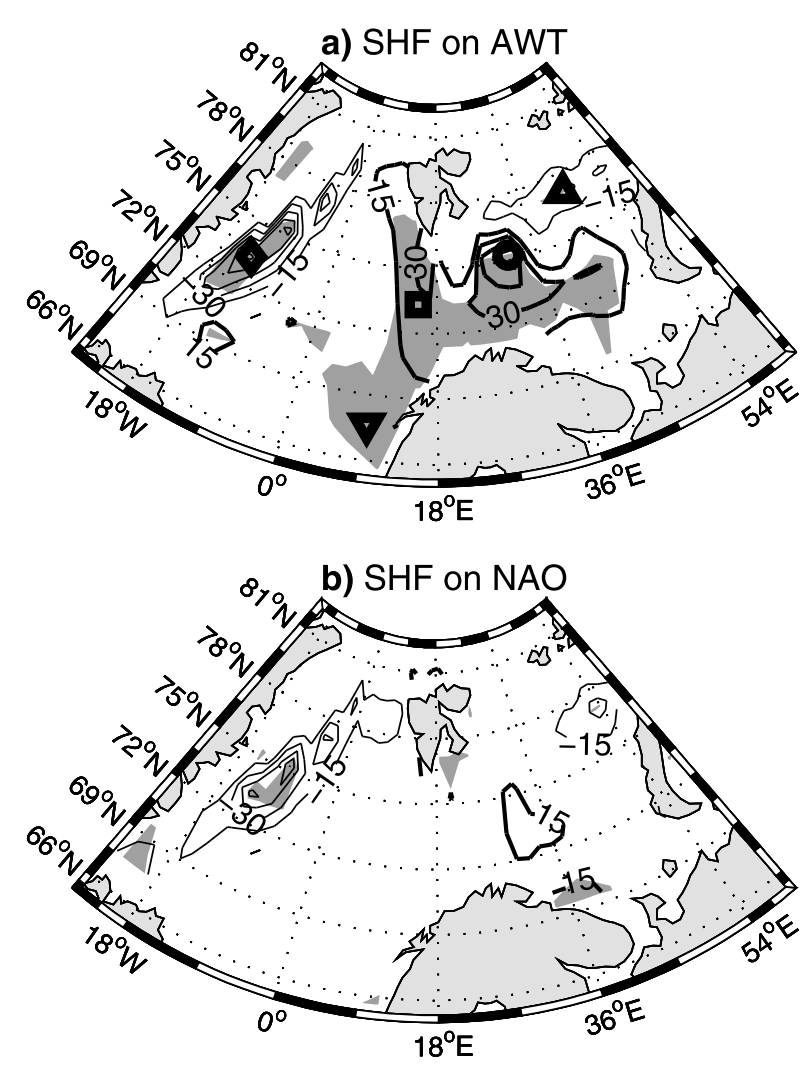

Figure 5. Late winter anomalies of the total SHF in the Nordic Seas area in the 1982-2005 period regressed onto (a) the following summer AWT index (Figure 4, circles) and (b) the concomitant (late winter) NAO index (Figure 4c, squares). The contour interval is $15 \mathrm{~W} \mathrm{~m}^{-2}$ per unit AWT and NAO index, respectively, and the zero contour is omitted. Thick contours (positive values) correspond to downward SHF anomalies while thin contours (negative values) correspond to upward SHF anomalies. Dark shading denotes anomalies statistically significant at the $95 \%$ confidence level. In Figure 5a, the circle, diamond and triangle indicate the locations of maximum late winter SHF anomalies in the Barents Sea open water, Greenland Sea MIZ, and Barents Sea MIZ, respectively, while the upside-down triangle and square indicate additional points in the open water for which evolution of the time lagged regression coefficients is shown in Figure 8a.

AWT-associated late winter anomalies of SHF in the MIZ, one in the Greenland Sea (Figure 5a, diamond) and one in the Barents Sea (Figure 5a, triangle). Indices of regional variability are also constructed by averaging anomalies of surface variables over the entire Nordic Seas (Figure 1a, full domain) or over the climatological MIZs and open ocean parts of the Nordic Seas, separately east and west of $15^{\circ} \mathrm{E}$. The climatological MIZ (respectively, open ocean area) for a given season is defined as the area where the long-term mean of SIC is in the range 5-90\% (respectively, smaller than $5 \%$ ).

[19] An index of regional wind variability, the on ice wind (OIW) index, has been calculated as the normalized difference of the SLP anomalies between the southern tip of
Novaya Zemlya $\left(57.5^{\circ} \mathrm{E}-70^{\circ} \mathrm{N}\right)$ and the southern tip of Spitsbergen $\left(17.5^{\circ} \mathrm{E}-77.5^{\circ} \mathrm{N}\right)$. These locations (Figure 1b, crosses) have been selected among different pairs of points across the Barents Sea as those providing the highest correlations of the associated anomalous SLP difference with the AWT index in cold seasons. Positive (negative) values of the index correspond to geostrophic wind anomalies across the Barents Sea MIZ directed inward (outward) the ice pack (see Figure 4b, squares, for the late winter OIW index).

[20] To characterize the large-scale atmospheric variability, we use the winter (December-March) NAO index (hereafter referred to as a station-based index) defined as the SLP difference between Lisbon (Portugal) and Stykkisholmur (Iceland) [Hurrell, 1995], updated from http://www.cgd.ucar. edu/cas/jhurrell/, and then detrended and renormalized for the period under study. Alternatively, following Hurrell et al. [2003], we also use a pattern-based NAO index based on the principal component associated with the leading mode of the SLP anomaly distribution calculated over the North Atlantic sector $\left(90^{\circ} \mathrm{W}-40^{\circ} \mathrm{E}, 20-70^{\circ} \mathrm{N}\right)$ for the period of study (see Figure 4c, squares, for the late winter NAO index).

\section{Interannual Atlantic Water Temperature and Surface Atmospheric Variability}

\subsection{Summer AWT Anomalies}

[21] The period under study is marked by an Arctic intensification of the global warming which started in about 1980 [Johannessen et al., 2004]. The series of AWT in the BSO area (Figure $2 \mathrm{~b}$, circles) shows a warming trend of $\sim 0.25^{\circ} \mathrm{C}$ per decade (Figure $2 \mathrm{~b}$, dashed line). This trend is much larger than the trend in the global mean temperature of the upper $(0-300 \mathrm{~m})$ ocean from 1955 to 2003, which is $\sim 0.04^{\circ} \mathrm{C}$ per decade [Levitus et al., 2005]. However, the AWT trend is not statistically significant at the $95 \%$ confidence level (see Appendix A). The AWT anomalies around the trend (Figure $2 \mathrm{c}$ ) have a large standard deviation $\left(\sim 0.4^{\circ} \mathrm{C}\right)$ and explain $85 \%$ of the total AWT variance.

[22] Two warm and two cold prominent events are found in the BSO area in the last two decades of the 20th century (Figure 2c): W1 (1983-84), C1 (1985-88), W2 (1990-92), and C2 (1997-98). The AWT anomalies reach $\sim 0.6^{\circ} \mathrm{C}$ during these events and so are larger than their estimated uncertainty (see the 95\% confidence intervals in Figure 2b). The passage from $\mathrm{W} 1$ to $\mathrm{C} 1$ and from $\mathrm{C} 1$ to $\mathrm{W} 2$ is abrupt $\left(\sim 0.8^{\circ} \mathrm{C}\right.$ in 1 year), but the passage from $\mathrm{W} 2$ to $\mathrm{C} 2$ occurs in two steps, from 1992 to 1993 and after a secondary warming in 1995. W1, C1, and W2 are named after Furevik [2001], who identified analogous events on hydrographic sections located to the south, east, and north of our BSO box. Similar events were also documented by independent observations on the shelf slope in Fram strait [Saloranta and Haugan, 2001]. C2 was reported from hydrographic stations located within the BSO box [Schlichtholz and Goszczko, 2005] and also observed farther north [Schauer et al., 2004; Schlichtholz and Goszczko, 2006].

[23] The passage from C2 to a warm event (W3) at the turn of the century (1999-2000) is as abrupt as the W1/C1 and $\mathrm{C} 1 / \mathrm{W} 2$ shifts (Figure 2c). W3 is followed by a secondary cooling and warming in 2001 and 2002, respectively. The AWT series ends with a single-year cold event (C3) in 2003 followed by a warm event (W4) in 2004-2005. The peak 

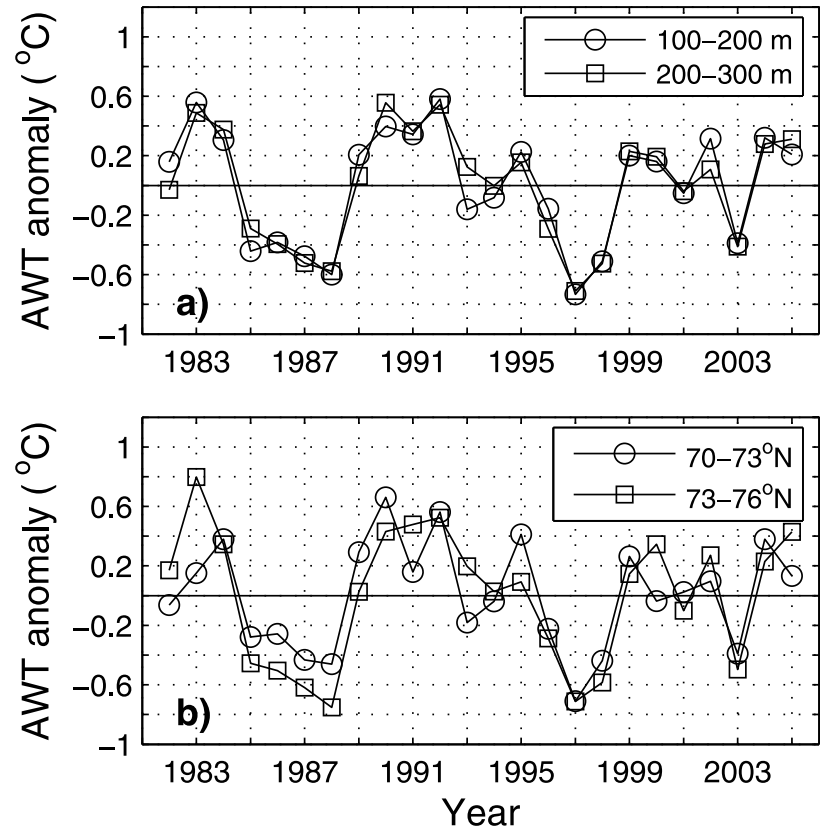

Figure 6. The anomalies of AWT from 1982 to 2005 averaged over (a) the 100-200 $\mathrm{m}$ (circles) and 200-300 m (squares) sublayers and (b) the southern (circles) and northern (squares) halves of the BSO area (Figure 1, box).

anomalies of all events after $\mathrm{C} 2$ are relatively small $(\sim 0.2-$ $0.4^{\circ} \mathrm{C}$ ) and close to the relatively large estimates of their uncertainty (Figure 2b). This large uncertainty mainly reflects a relatively low number of hydrographic stations after $\mathrm{C} 2$ (Figure 2a). We have, however, confidence in W3, C3, and W4 because they are corroborated by independent observations from the West Spitsbergen current [Schauer et al., 2004; Polyakov et al., 2005b; Walczowski and Piechura, 2006].

[24] The AWT anomalies have practically the same magnitude and correlate high between the upper and lower halves of the core of the Atlantic water layer (Figure 6a) and between the southern and northern halves of the BSO box (Figure $6 \mathrm{~b})(r=0.96$ and 0.82 , respectively). Note that a further increase of the meridional resolution of the subsampling leads to statistically unreliable or even incomplete time series (not shown). The root-mean-squared difference of the AWT anomalies between the southern and northern regions $\left(\sim 0.25^{\circ} \mathrm{C}\right)$ is smaller than the root-mean-squared uncertainty of the AWT in each of the two regions $\left(\sim 0.3^{\circ} \mathrm{C}\right)$. The quite strong coherence between the AWT anomalies in the southern and northern halves of the BSO box is consistent with the scenario of their southern origin and propagation toward the Arctic Ocean via Fram strait [e.g., Polyakov et al., 2005b]. However, the along-slope distribution of the composite temperature difference between the "BSO warm summers" ( $W_{0}$ epoch) and the "BSO cold summers" $\left(C_{0}\right.$ epoch) reveals that the AWT anomalies are not quite uniform in the BSO box (Figure 3a, circles between the bold vertical lines). The difference is extreme $\left(\sim 1.5^{\circ} \mathrm{C}\right)$ at $74^{\circ} \mathrm{N}$ and drops to zero at $70^{\circ} \mathrm{N}$. Large $\left(\sim 1^{\circ} \mathrm{C}\right)$ and significant (at the $95 \%$ confidence level) positive differences are found between $71.5^{\circ} \mathrm{N}$ and $78.5^{\circ} \mathrm{N}$ (Figure $3 \mathrm{a}$, filled circles). Significant positive differences of twice smaller magnitude $\left(\sim 0.6^{\circ} \mathrm{C}\right)$ appear also near the Svinøy mooring (point $\mathrm{S}$ in Figure $1 \mathrm{~b}$ ) while nonsignificant negative differences are found between $66^{\circ} \mathrm{N}$ and the BSO box. It is therefore clear that the coherence of the AWT anomalies on the shelf slope region occurs only over limited spatial scales. This implies that either persistent forcing of these AWT anomalies from the North Atlantic is not dominant during the period considered or that a strong modification of these anomalies would occur within the Nordic Seas.

[25] Based on continuous temperature records from the Svinøy and Fram strait moorings, Polyakov et al. [2005b] estimated the propagation speed of some recent AWT anomalies to be $\sim 4 \mathrm{~cm} \mathrm{~s}^{-1}$. An anomaly with this speed should travel $\sim 1200 \mathrm{~km}$ in 1 year so the band of coherent AWT anomalies identified on the $500 \mathrm{~m}$ isobath between $71.5^{\circ} \mathrm{N}$ and $78.5^{\circ} \mathrm{N}$ (Figure $3 \mathrm{a}$, circles) should be found 1 year earlier between the Svinøy mooring and the BSO box. The along-slope distribution of the composite temperature difference between the epochs $W_{-1}$ and $C_{-1}$ preceding by 1 year the "BSO warm summers" and the "BSO cold summers" (Figure 3a, triangles) resembles the corresponding distribution of the difference between the $W_{0}$ and $C_{0}$ epochs (Figure 3a, circles) indicating a local autocorrelation of the anomalies rather than their propagative character. Therefore, either the propagation speed of the AWT anomalies inferred by Polyakov et al. [2005b] on the basis of two warming events is not representative of a larger population of anomalies or the anomalies of southern origin are often erased or amplified by processes occurring north of the Svinøy mooring.

[26] The maximum composite temperature difference between the $W_{0}$ and $C_{0}$ epochs along the shelf slope (Figure $3 \mathrm{a}$, circles) occurs at $74^{\circ} \mathrm{N}$ suggesting that the AWT anomalies in the BSO area may originate in the Barents Sea. The strongest outflow from the Barents Sea occurs on the northern slope of the Bear Island trough below the $300 \mathrm{~m}$ depth [e.g., Skagseth, 2008], but the outflow in the 100 $300 \mathrm{~m}$ layer is also considerable. A calculation of the vertically averaged northwestward flow based on the mean annual velocities recorded for 4 years at $19.3^{\circ} \mathrm{E}$ and $73.5^{\circ} \mathrm{N}$ [Ingvaldsen et al., 2004, Table 1] yields $\sim 4 \mathrm{~cm} \mathrm{~s}^{-1}$ for the $100-300 \mathrm{~m}$ layer and $\sim 7 \mathrm{~cm} \mathrm{~s}^{-1}$ for the $300-450 \mathrm{~m}$ layer. The zonal distributions of the composite temperature difference between the $W_{0}$ and $C_{0}$ epochs at $74^{\circ} \mathrm{N}$ show that the temperature anomalies are coherent between the two layers (Figure 3b). In both layers, statistically significant differences extend from the Barents Sea to the Arctic front at $8^{\circ} \mathrm{E}$ but are extreme on the Barents Sea side of the BSO box. In the Barents Sea, the differences are large (up to $\sim 1.2^{\circ} \mathrm{C}$ ) and vertically uniform while west of $17^{\circ} \mathrm{E}$ the differences in the deeper layer become progressively smaller than the differences in the upper layer. Presumably, horizontal mixing in the outflow area from the Barents Sea is stronger in the upper layer than below. This is also suggested by a decrease of the kinetic energy of daily velocity fluctuations with depth in this area [Ingvaldsen et al., 2004]. The vertical uniformity of the strong summer AWT anomalies at the exit from the Barents Sea is indicative of generation of these anomalies in a deep mixed layer by air-sea heat exchanges during the previous cooling period. This scenario will be supported in 

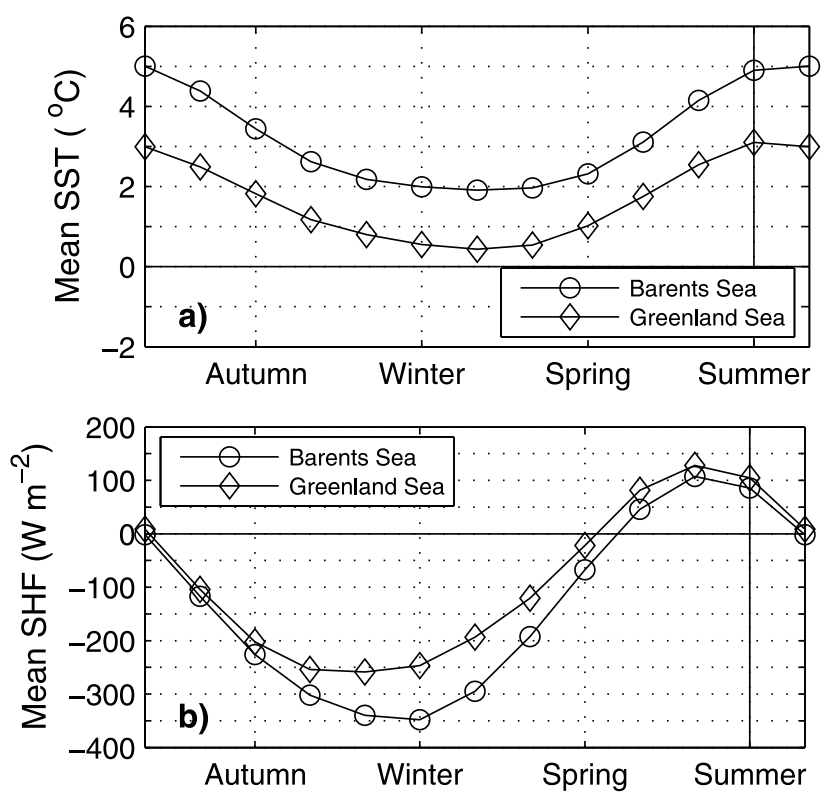

Figure 7. Seasonal evolution of the long-term mean (a) SST (in degrees Celsius) and (b) SHF (in watts per square meter, positive downward) in the 1982-2005 period near the Barents Sea ice edge in the Hopen trench area (circles) and in the Greenland Sea MIZ (diamonds) at points marked in Figure 5a with the circle and diamond, respectively. Shown are 4 month averages with a step of 1 month. Winter (summer) corresponds to the December-March (JuneSeptember) average.

the following sections by investigation of regional patterns of variability in SST and atmospheric fields.

\subsection{Relation to Late Winter Surface Heat Flux Anomalies}

[27] Observations reveal that atmospheric influence on the Atlantic water core temperature occurs only in the cold season of strong turbulent surface ocean heat loss. In the southern Norwegian Sea, for instance, the cooling typically starts in October and ends between January and April (our late winter season) when the mixed layer depth descends to the base of the Atlantic water core $(\sim 300 \mathrm{~m})$ [Nilsen and Falck, 2006]. Vertical mixing is not strong enough in the rest of the year when strong solar radiation and a lateral spread of coastal waters create a shallow ( $20 \mathrm{~m})$, warm, and fresh mixed layer shielding the Atlantic water core from atmospheric forcing. Judging from the seasonal evolution of the long-term mean SST, late winter is also the coldest season in the Barents Sea (Figure 7a, circles) and Greenland Sea (Figure 7a, diamonds). The corresponding extreme heat loss from the ocean surface occurs slightly earlier, in winter over the Barents Sea (Figure 7b, circles), and in early winter over the Greenland Sea (Figure $7 \mathrm{~b}$, diamonds). However, we focus our analysis on late winter (lag -5 months), when the SHF anomalies associated with summer AWT anomalies in the BSO area are the strongest all along the Atlantic water path from the Norwegian Sea to the Barents Sea (Figure 8a).
[28] The late winter pattern of the AWT-associated total SHF anomalies appears as a dipole with reduced (respectively, increased) ocean surface heat loss in the open ocean (respectively, Barents Sea and Greenland Sea MIZs) (Figure 5a) corresponding to positive AWT anomalies in the BSO area. The reduction of the ocean surface heat loss is maximum in the Hopen trench area where it reaches $70 \mathrm{~W} \mathrm{~m}^{-2}$ (at the circle in Figure 5a) while the increase of the heat loss is maximum in the Greenland Sea MIZ $\left(\sim 80 \mathrm{~W} \mathrm{~m}^{-2}\right.$ at the diamond in Figure 5a). Secondary extrema appear in both lobes of the dipole. In particular, one notices a marginally significant increase of the ocean surface heat loss in the Barents Sea MIZ ( $\sim 0 \mathrm{~W} \mathrm{~m}^{-2}$ at the triangle in Figure 5a). In contrast to the total SHF, the AWT-associated anomalies of SAT (Figure 9a, contours) and SHUM (Figure 9b) have the same sign throughout the Nordic Seas and correspond to warmer and moister conditions for positive AWT anomalies. Maximum values appear in the MIZs and are slightly larger over the Barents Sea $\left(3.5^{\circ} \mathrm{C}\right.$ and $\left.0.32 \mathrm{~g} \mathrm{~kg}^{-1}\right)$ than over the Greenland Sea $\left(2.6^{\circ} \mathrm{C}\right.$ and $\left.0.24 \mathrm{~g} \mathrm{~kg}^{-1}\right)$.
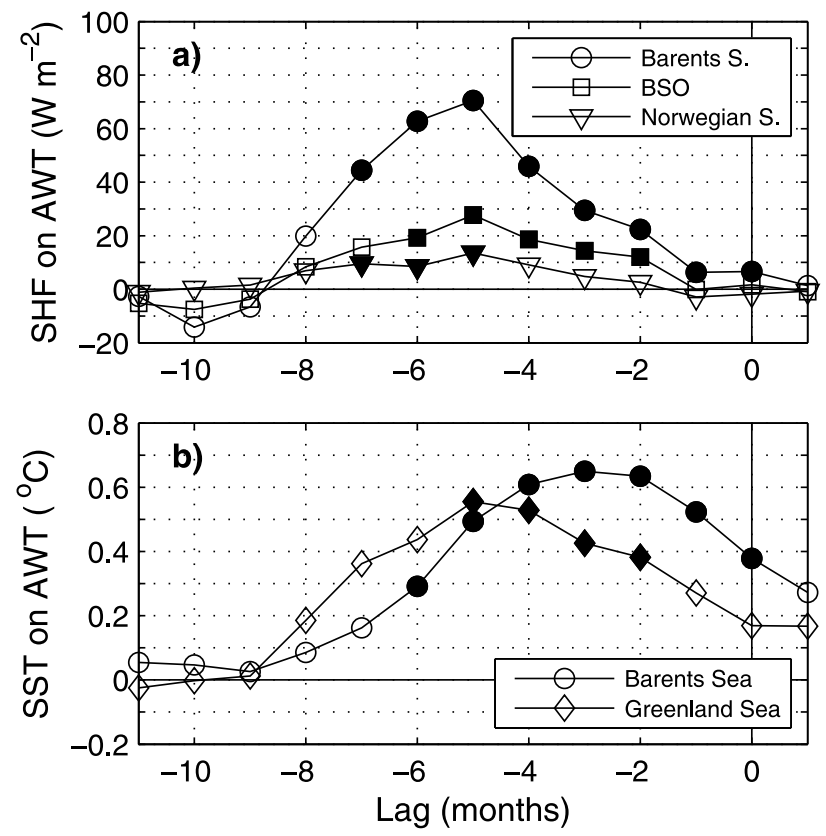

Figure 8. Time-lagged regression coefficients of (a) the total SHF anomalies (in watts per square meter per unit AWT index, positive downward) over the the Barents Sea open water (circles), BSO (squares), and Norwegian Sea (upside-down triangles) at points marked in Figure 5a with the circle, square, and upside-down triangle, respectively, and (b) SST anomalies (in degrees Celsius per unit AWT index) in the Barents Sea open water (circles) and Greenland Sea MIZ (diamonds) at points marked in Figure 5a with the circle and diamond, respectively, regressed onto the summer AWT index in the 1982-2005 period (Figure 4, circles). Filled symbols denote anomalies statistically significant at the $95 \%$ confidence level. Negative (positive) lags correspond to surface variables leading (lagging) the AWT index so that lag -6 (respectively, -5 ) months refers to the winter (respectively, late winter) preceding a given summer, and so on. 

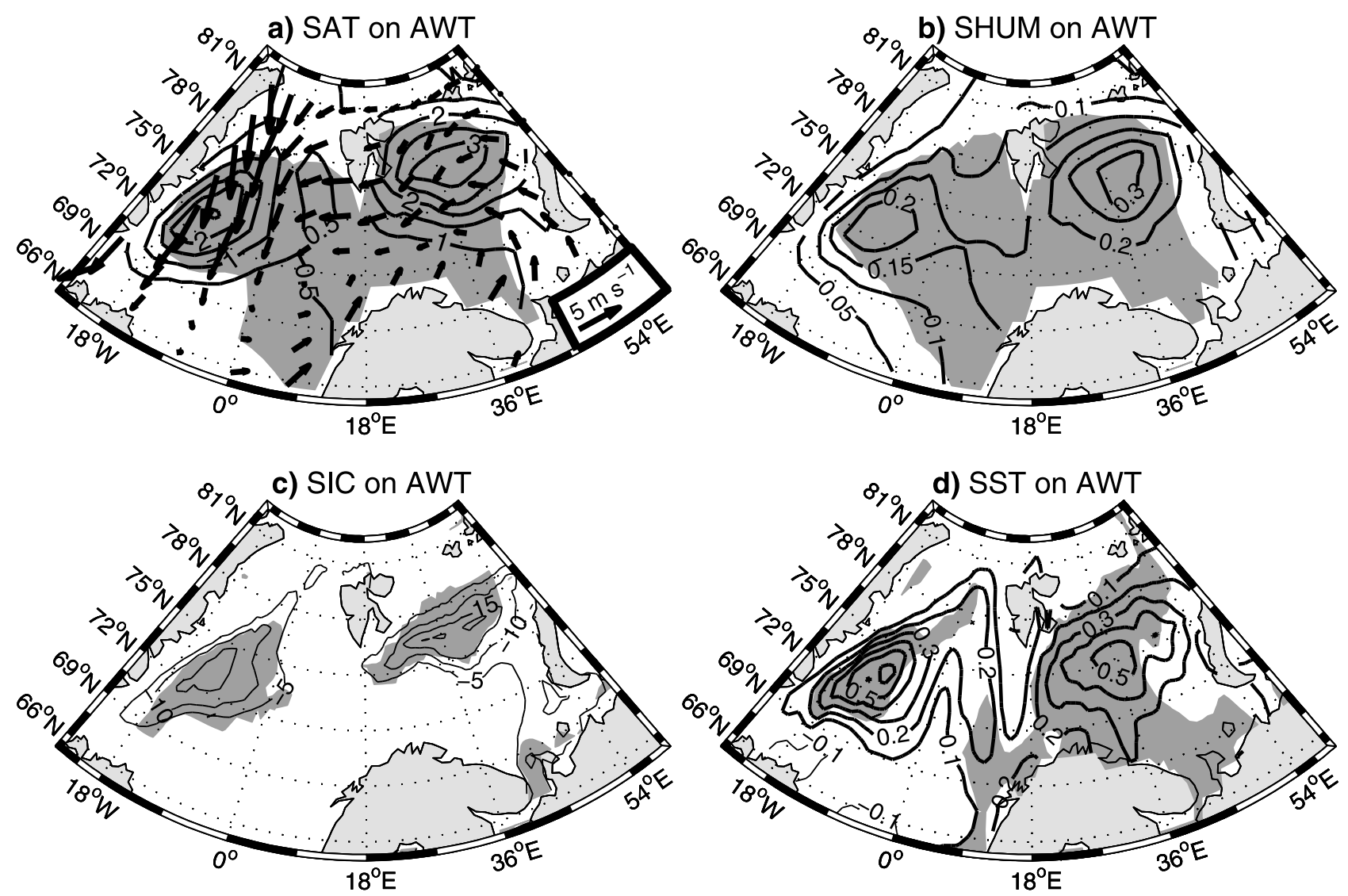

Figure 9. Late winter anomalies of (a) SAT, (b) SHUM, (c) SIC, and (d) SST in the Nordic Seas area in the 1982-2005 period regressed onto the following summer AWT index (Figure 4, circles). In Figures 9a-9d, the contour interval is $0.5^{\circ} \mathrm{C}, 0.05 \mathrm{~g} \mathrm{~kg}^{-1}, 5 \%$, and $0.1^{\circ} \mathrm{C}$ per unit AWT index, respectively. Dark shading denotes anomalies statistically significant at the 95\% confidence level. In Figure 9a, arrows represent the long-term (1982-2005) mean of the late winter surface wind velocity (in m s ${ }^{-1}$, scaled as in the right-bottom corner, subsampled in longitude).

[29] As expected for a cold season, the late winter SHF anomalies are primarily dominated by turbulent fluxes (see Table 2 for the magnitude of all contributions at the locations of maximum SHF variability in the open ocean and in the MIZs). The contribution of the sensible heat flux is larger than that of the latent heat flux, contributing to $71 \%$ of the total SHF anomaly in the Hopen trench area. The negative lobe of the SHF pattern over the MIZs, which cannot be the result of the surface atmosphere warming, is consistently associated with a reduction of the sea ice cover (Figure 9c). The anomalous fluxes arise because of a large contrast between surface temperature and humidity across the ice edge. Ice edge retreat typically favors enhanced ocean surface heat loss to the atmosphere in ice-freed areas [e.g., Deser et al., 2000]. Mechanisms responsible for the ice edge retreat as well as other sources of SAT and SHUM variability in the MIZs will be discussed in section 5 .

\subsection{Role of Air-Sea Interactions in the Barents Sea Open Water}

[30] The existence of a broad band of large, significant AWT-associated SHF anomalies extending from the Norwegian Sea to the Barents Sea (Figure 5a, dark shading) suggests that air-sea heat exchanges in this area could play a central role in the formation/maintenance of the AWT anomalies in the BSO area. The presummer evolution of the SHF anomalies indicates a stronger influence of the late winter air-sea heat flux anomalies throughout the area (Figure 8a). Still, the increasing magnitude of the anomalies from the Norwegian Sea (upside-down triangles) toward the Barents Sea ice edge (circles) throughout the presummer seasons suggests that anomalies over the Barents Sea may

Table 2. AWT-Associated Late Winter Anomalies of the Sensible $Q_{S}^{\prime}$, Latent $Q_{L}^{\prime}$, Net Shortwave Radiative $Q_{S W}^{\prime}$, and Net Longwave Radiative $Q_{L W}^{\prime}$ Contributions to the Total SHF (Positive Downward) in the Hopen Trench Area, Greenland Sea MIZ, and Barents Sea MIZ in the 1982-2005 Period $^{\mathrm{a}}$

\begin{tabular}{lcccc}
\hline Variable & Units $^{\mathrm{b}}$ & Hopen Trench & GS-MIZ & BS-MIZ \\
\hline$Q^{\prime}{ }_{S}$ & $\mathrm{~W} \mathrm{~m}^{-2}$ & $\mathbf{5 0 . 4}$ & $\mathbf{- 5 4 . 1}$ & $\mathbf{- 2 9 . 0}$ \\
$Q^{\prime}{ }_{L}$ & $\mathrm{~W} \mathrm{~m}^{-2}$ & $\mathbf{1 4 . 4}$ & $\mathbf{- 2 3 . 2}$ & $\mathbf{- 1 4 . 2}$ \\
$Q^{\prime}{ }^{\prime}{ }_{W}$ & $\mathrm{~W} \mathrm{~m}{ }^{-2}$ & 2.0 & 2.7 & $\mathbf{3 . 6}$ \\
$Q^{\prime}{ }_{L W}$ & $\mathrm{~W} \mathrm{~m}{ }^{-2}$ & $\mathbf{3 . 7}$ & -4.1 & -2.1 \\
\hline
\end{tabular}

${ }^{\mathrm{a}}$ The anomalies in the Hopen Trench area, Greenland Sea MIZ (GSMIZ), and Barents Sea MIZ (BS-MIZ) are given for points marked with a circle, diamond, and triangle in Figure 5a, respectively. Anomalies significant at the $95 \%$ (99\%) confidence level are bold (italic).

${ }^{b}$ Per unit AWT index. 

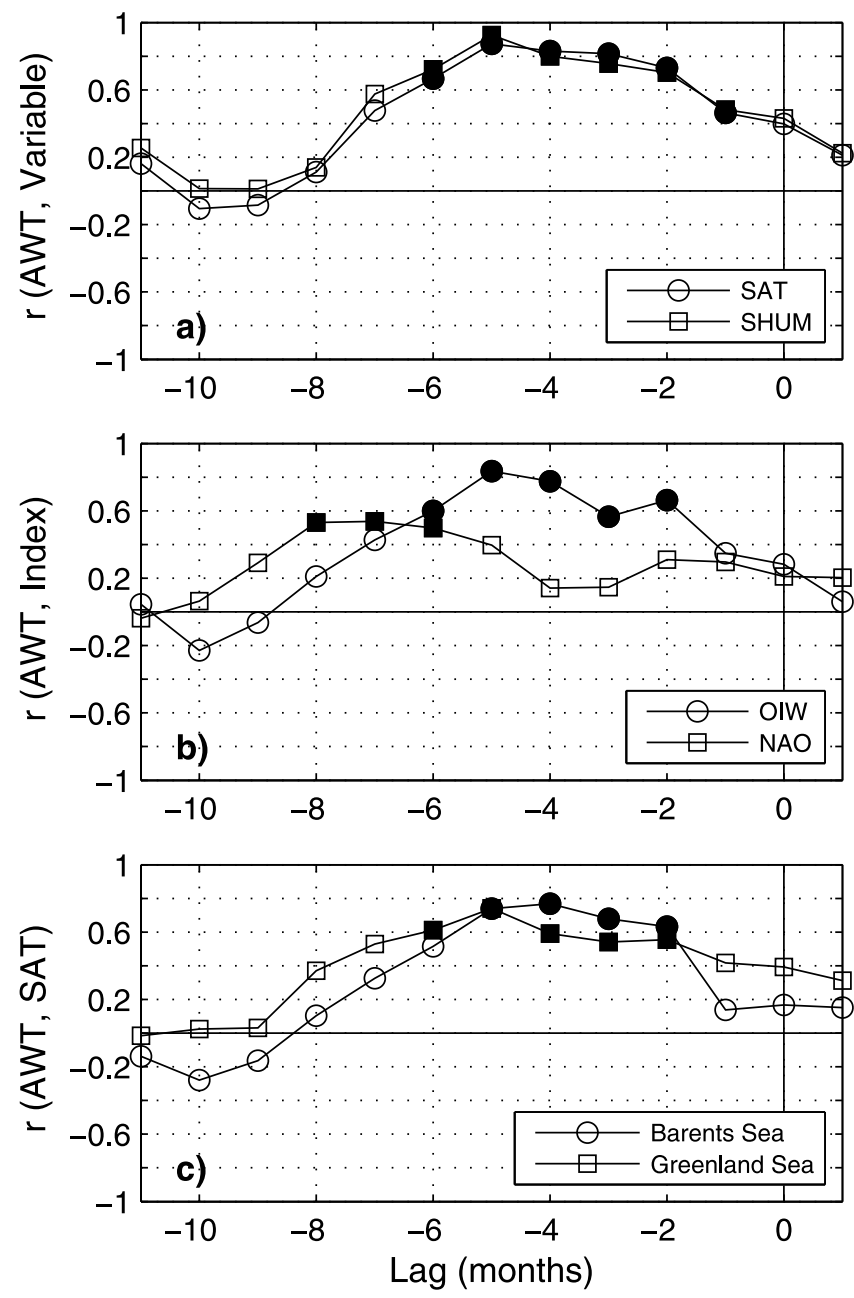

Figure 10. Time-lagged correlations of the summer AWT index in the 1982-2005 period (Figure 4, circles) with (a) the SAT (circles) and SHUM (squares) anomalies averaged over the Barents Sea climatological open water, (b) OIW index defined in Table 1 (circles) and the pattern-based NAO index (squares), and (c) SAT anomalies in the Barents Sea (circles) and Greenland Sea (squares) MIZs at the triangle and diamond in Figure 5a, respectively. Sign convention for lags as in Figure 8. Filled symbols denote correlations statistically significant at the $95 \%$ confidence level.

play the most significant role. This hypothesis is further supported by the distribution of the correlation of the late winter SHF anomalies with the AWT index (not shown) which exhibits values exceeding 0.7 over most of the Barents Sea open water and as high as 0.86 in the Hopen trench area (see Figure 4a, circles and squares, for comparison of the time series) while the corresponding values over the Norwegian Sea are lower than 0.65 .

[31] There is a strong statistical evidence that the AWT variability in the BSO area is tightly linked to the air-sea interactions over the Barents Sea. Indeed, the part of the AWT anomalies (Figure 2c) that is not explained by a linear relationship to the SHF anomalies in the Hopen trench area (Figure 4a, squares) is not correlated either with the SHF anomalies over the Norwegian Atlantic current $(r=0.20$ at the upside-down triangle in Figure 5a) or with the SHF anomalies in the BSO area $(r=0.16$ at the square in Figure 5a). In contrast, the part of the AWT anomalies unexplained by the SHF anomalies over the Norwegian Atlantic current or the BSO area is significantly (at the $95 \%$ confidence level) correlated with the SHF anomalies in the Hopen trench area ( $r=0.63$ and $r=0.49$, respectively). Therefore, the AWT anomalies in the BSO area are linked to the SHF anomalies over the Norwegian Sea only to the extent to which the latter are coherent with the SHF anomalies over the Barents Sea.

[32] The late winter SHF anomalies off the Barents Sea ice edge are associated with SAT and SHUM anomalies of same sign, namely warmer and moister surface atmospheric conditions (Figures 9a and 9b) are concomitant with a reduced sensible and latent heat loss from the ocean surface (Table 2). In contrast to the MIZs, this is consistent with a scenario where SAT and SHUM anomalies control SHF anomalies which in turn generate AWT anomalies. This control must be very efficient, as indicated by extremely high peak correlations of the AWT index with the SAT and SHUM anomalies over the Barents Sea open water which reach 0.87 (Figure 10a, circles) and 0.92 (Figure 10a, squares), respectively.

[33] If the summer AWT anomalies in the BSO area are indeed formed by anomalous air-sea interactions in the preceding seasons, then the AWT-associated SST anomalies at the formation site should be larger, assuming no amplification of the original anomalies by oceanic processes during their propagation. More precisely, they should exceed at least $\sim 0.4^{\circ} \mathrm{C}$, the standard deviation of the AWT anomalies in the $\mathrm{BSO}$ area (Figure 2c), or even be larger than $\sim 0.5^{\circ} \mathrm{C}$ to account for the local temperature variations within the BSO area (Figure 3a, circles between the bold vertical lines). The SHF anomalies over the Norwegian Sea are too weak to produce sufficiently strong oceanic heat variability. The AWT-associated SST anomalies south of the BSO area reach only $\sim 0.2^{\circ} \mathrm{C}$ in late winter (Figure 9d). In contrast, the AWTassociated SST anomalies in the Barents Sea exceed $0.5^{\circ} \mathrm{C}$ already in late winter (Figure 9d) and, in the Hopen trench area, reach a maximum of $0.65^{\circ} \mathrm{C}$ in spring (lag -3 months; Figure $8 \mathrm{~b}$, circles). The correlation of these spring anomalies with the AWT anomalies of the following summer in the BSO area is as high as 0.91 (see Figure 4a, circles and triangles, for comparison of the time series). This timing is consistent with a scenario in which spring SST anomalies in the open Barents Sea act as the essential vector to connect the late winter air-sea heat flux variability in the Barents Sea and the summer heat content variability in the Atlantic water layer in the BSO area. The exact mechanism will be discussed in section 4.1 based on a detailed analysis of the ocean mixed layer heat budget. Additionally, the 2 month lag between the peak atmospheric forcing (Figure 8a) and the peak oceanic response in the Hopen trench area (Figure 8b) is consistent with the damping effect of the SST anomalies on the SHF anomalies which create them [Frankignoul et al., 1998].

\subsection{Link to Atmospheric Circulation Over the Nordic Seas}

[34] The pattern of AWT-associated late winter SLP anomalies (Figure 11a) is dominated by a low-pressure cell centered over the Nordic Seas and a high-pressure cell over 
a) SLP on AWT

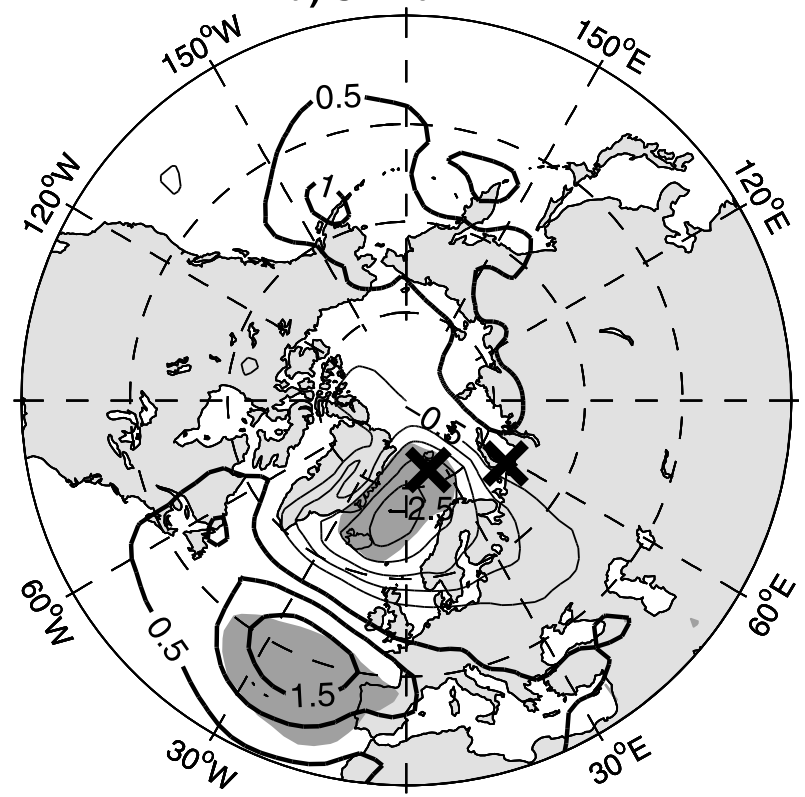

b) SLP on NAO

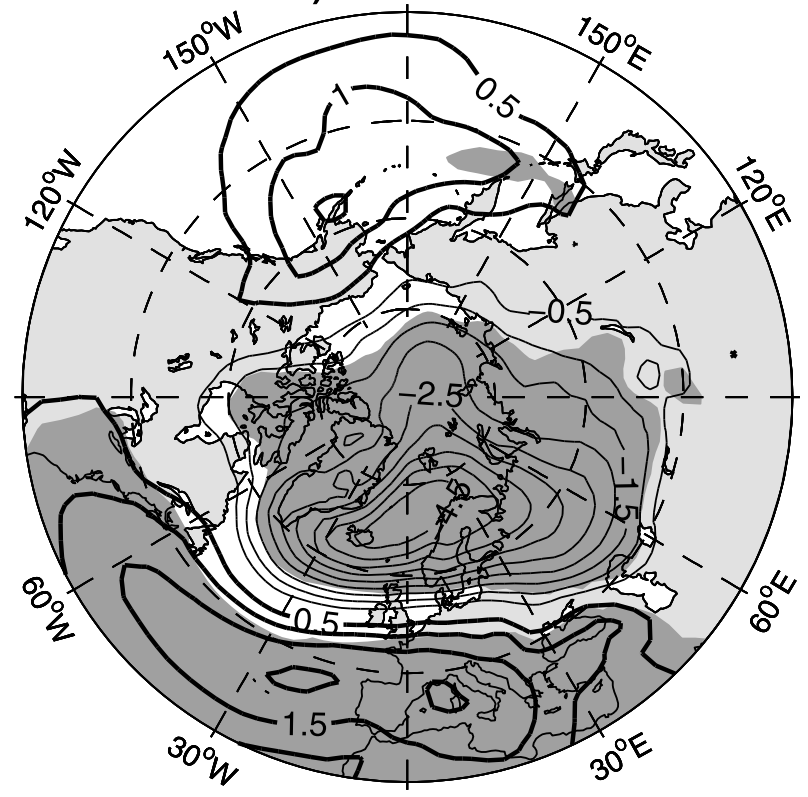

Figure 11. Late winter SLP anomalies over the extratropical Northern Hemisphere in the 1982-2005 period regressed onto (a) the following summer AWT index (Figure 4, circles) and (b) the concomitant (late winter) NAO index (Figure 4c, squares). In Figure 11a and 11b, the contour interval is $0.5 \mathrm{hPa}$ per unit AWT and NAO index, respectively. Dark shading denotes anomalies statistically significant at the $95 \%$ confidence level. In Figure $11 \mathrm{a}$, the crosses indicate the points for calculation of the OIW index defined in Table 1.

the North Atlantic. In addition, a North Pacific high-pressure cell extends westward over the eastern Arctic marginal seas limiting the extension of the low pressure cell over the Arctic Ocean and northern Asia. As a result, the isobars are squeezed over the Barents Sea where significant AWTassociated surface wind anomalies appear (Figure 12a, arrows and shading). These anomaly patterns suggest that the AWT variability in the BSO area should be related to anomalous winds across the Barents Sea ice edge. In the Hopen trench area (marked with a circle), the anomalous winds are nearly perpendicular to the mean SAT (Figure 12a, contours) and SHUM (Figure 12b, contours) fronts aligned with the ice edge (see the limit of dark shading in Figure 1b).

[35] It is the anomalous direction and not magnitude of the wind which is crucial for generation of the heat variability in the Barents Sea. Indeed, the AWT-associated wind speed anomaly in the Hopen trench area is practically zero $\left(<0.1 \mathrm{~m} \mathrm{~s}^{-1}\right.$, not shown). The AWT-associated wind anomaly pattern (Figure 12a) rather includes a pronounced spatial distortion of the general cyclonic circulation over
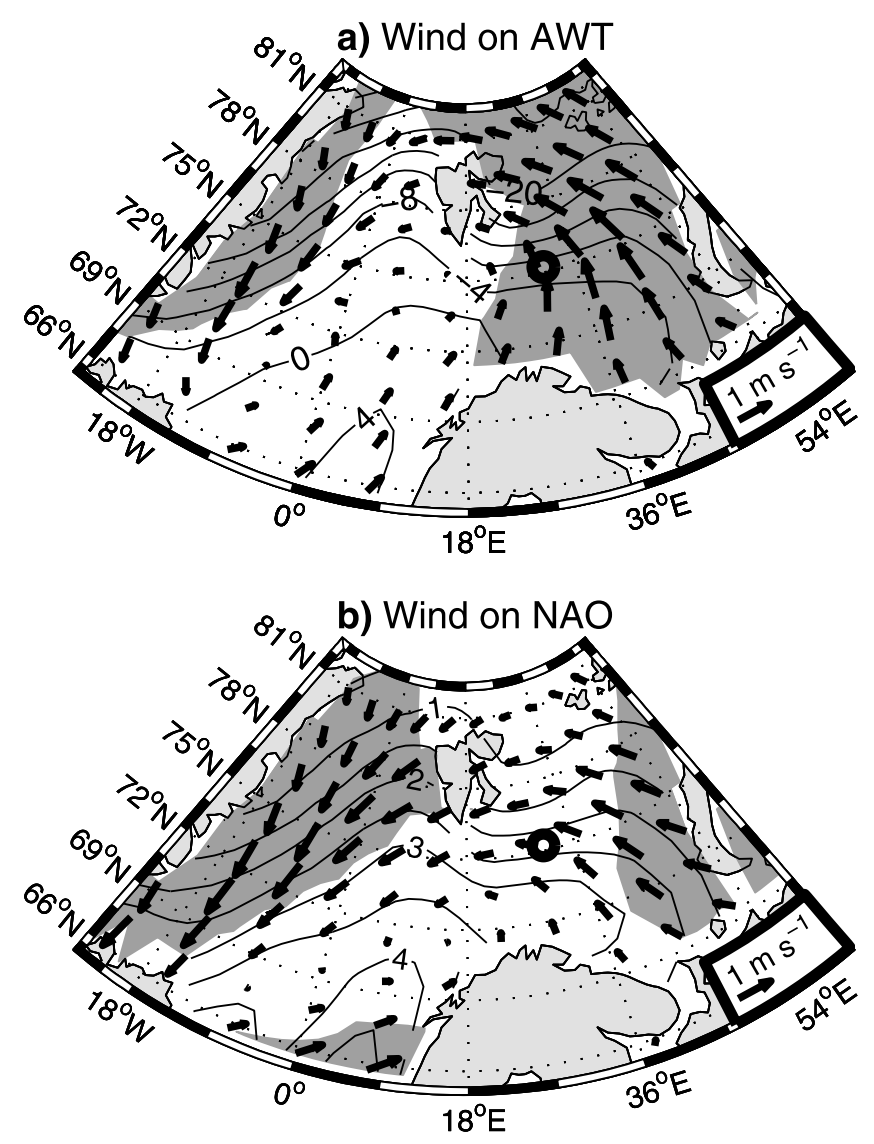

Figure 12. Late winter anomalies of the surface wind velocity (arrows) in the Nordic Seas area in the 19822005 period regressed onto (a) the following summer AWT index (Figure 4, circles) and (b) the concomitant (late winter) NAO index (Figure 4c, squares). In Figures 12a and $12 \mathrm{~b}, \mathbf{u}_{a}^{\prime}$ (scaled as in the right-bottom corner) is in meters per second per unit AWT and NAO index, respectively, while areas where either the zonal or meridional component of $\mathbf{u}_{a}^{\prime}$ is statistically significant at the $95 \%$ confidence level are shaded. In Figures 12a and 12b, the contours represent the long-term (1982-2005) mean of the late winter SAT (in degrees Celsius) and SHUM (in grams per kilogram), respectively, and the circle indicates the location of the largest AWTassociated downward SHF anomaly (circle in Figure 5a). 
the Nordic Seas (Figure 9a, arrows). Over the central Barents Sea, the AWT-associated winds are in fact perpendicular to the mean winds.

[36] As a measure of the strength of the surface wind across the Barents Sea ice edge, the OIW index captures all geostrophic wind anomalies between the crosses in Figure 11a. From winter to late spring (lags -6 to -2 months), that is, over the period of large $\left(>20 \mathrm{~W} \mathrm{~m}^{-2}\right) \mathrm{SHF}$ anomalies in the Hopen trench area (Figure 8a, circles), the OIW index is significantly correlated with the AWT anomalies of the subsequent summer in the BSO area (Figure 10b, circles). The late winter peak correlation is 0.84 (see Figure $4 \mathrm{~b}$ for comparison of the time series). The OIW-associated patten of the late winter SHF anomalies (not shown) is very similar to the corresponding AWT-associated pattern (Figure 5a). The correlation of the late winter OIW index (Figure 4b, squares) with the concomitant SHF anomalies in the Hopen trench area (Figure 4a, squares) is practically the same $(r=$ 0.84 ) as with the AWT index.

\subsection{Relation to the North Atlantic Oscillation}

[37] The AWT-associated late winter SLP pattern (Figure 11a) and the NAO-associated pattern (Figure 11b) share a low-pressure cell centered over the Nordic Seas and a high-pressure cell over the North Atlantic. However, in contrast to the AWT-associated pattern, the low-pressure cell in the NAO-associated pattern extends farther over the Arctic Ocean and northern Asia so that surface wind anomalies in the Hopen trench area are nearly parallel to the ice edge and nonsignificant (Figure 12b, arrows and shading). Instead of a distortion of the large-scale cyclonic circulation, the NAO-associated wind anomalies (Figure 12b) correspond to an intensification of this circulation (Figure 9a, arrows).

[38] The different AWT- and NAO-associated SLP distributions explain why the summer AWT anomalies in the $\mathrm{BSO}$ area are only moderately correlated with the NAO index. The correlation with the winter (lag -6 months) station-based NAO index is 0.56 (Table 1) and 0.49 for the corresponding pattern-based index (Figure 10b, squares). These estimates, though significant, are on the lower side of the range of correlations between the NAO index and previously analyzed temperature records from the BSO area or nearby locations. Comparison with estimates from other studies is, however, difficult as there is a time dependence of the AWT/NAO link. For instance, Saloranta and Haugan [2001] demonstrated that omission of the first 5 years from their AWT series in the 1970-1994 period resulted in a doubling of the correlation with the NAO index (from 0.4 to $\sim 0.8$ ). Moreover, in this and in most other studies of the AWT/NAO link [e.g., Dickson et al., 2000; Furevik, 2001], the data were low pass filtered with a 3 year cut-off period so the high correlations obtained in these studies might have been a consequence of the serial correlation. This can be illustrated using our AWT index and the winter stationbased NAO index that are still moderately correlated not only at lag -6 months $(r=0.56, p=0.02)$ but also at lag -18 months $(r=0.47, p=0.06)$. As a result, the correlations for the smoothed indices (3 year running means) are as high as 0.72 (lag -6 months) and 0.81 (lag -18 months) and so approximately the same as the correlations obtained in other studies using smoothed data. However, their significance ( $p=0.04$ and 0.01 , respectively) is not very different from the corresponding significance for the correlations of the unsmoothed indices.

[39] The relatively weak correlation of the AWT index with the previous winter NAO index is consistent with the small $\left(<20 \mathrm{~W} \mathrm{~m}^{-2}\right)$ and nonsignificant NAO-associated SHF anomalies in the Hopen trench area (Figure 5b). The latter imply that the close link of the summer AWT variability in the BSO area to the late winter SHF variability over the Barents Sea open water is not the expression of a common forcing by the NAO. This does not mean that the NAO does not have any impact on the AWT variability in the BSO area. A stronger correlation of the AWT index with the NAO than that of the late winter SHF anomalies over the central Barents Sea with the NAO (0.56 versus a maximum of 0.38 for the winter station-based NAO index) suggests that NAO could act on the AWT in the BSO area through additional mechanisms than SHF anomalies. One of the mechanisms could involve a link of the AWT variability with the variability on the western side of the Nordic Seas. There is indeed a strong response to the NAO in the Greenland Sea MIZ. In this area, significant NAO-associated SHF anomalies of more than $60 \mathrm{~W} \mathrm{~m}^{-2}$ are identified which are on same order of magnitude as those associated with the AWT index (Figure 5). Along the Greenland coast, surface wind anomalies are as strong as over the Barents Sea $\left(\sim 1 \mathrm{~m} \mathrm{~s}^{-1}\right)$ and have the same direction in both the NAOand the AWT-related patterns (Figure 12). The significant, though moderate correlation of the AWT index with the previous winter NAO index would then express a link of both indices to the variability on the western side of the Nordic Seas. The persistence of a lower correlation at lag -18 months may represent an impact of the variability in the Atlantic water inflow to the Nordic Seas or air-sea interactions over the southern Norwegian Sea.

\section{Mechanisms Connecting AWT Variability to Atmospheric Variability Over the Barents Sea Open Water}

\subsection{Formation and Export of Temperature Anomalies} in the Ocean Mixed Layer

[40] As discussed in section 3.3, the variability of the summer AWT in the BSO area is closely linked to earlier spring SST anomalies generated in the central Barents Sea. A close examination of the ocean surface layer heat budget allows to estimate to which extent these SST anomalies are indeed generated by the SHF anomalies identified in the same area and to analyze the mechanisms leading to their subsequent export toward the BSO area. Integrated over the mixed layer depth, the conservation equation for heat anomalies [Frankignoul, 1985] can be written as

$$
\begin{aligned}
\underbrace{\rho_{w} c_{w} \bar{h} \frac{\partial T_{o}^{\prime}}{\partial t}}_{Q_{T}^{\prime}}= & Q^{\prime}+H_{E}^{\prime}+\rho_{w} c_{w} \\
& \cdot\{-\underbrace{h^{\prime} \frac{\partial \bar{T}_{o}}{\partial t}}_{Q_{h}^{\prime}}+\underbrace{\left[w_{e}\left(T_{b}-T_{o}\right)\right]^{\prime}}_{Q_{e}^{\prime}}-\underbrace{\left(\mathbf{U}_{g} \cdot \nabla T_{o}\right)^{\prime}}_{H_{g}^{\prime}}\}+Q_{r}^{\prime},
\end{aligned}
$$



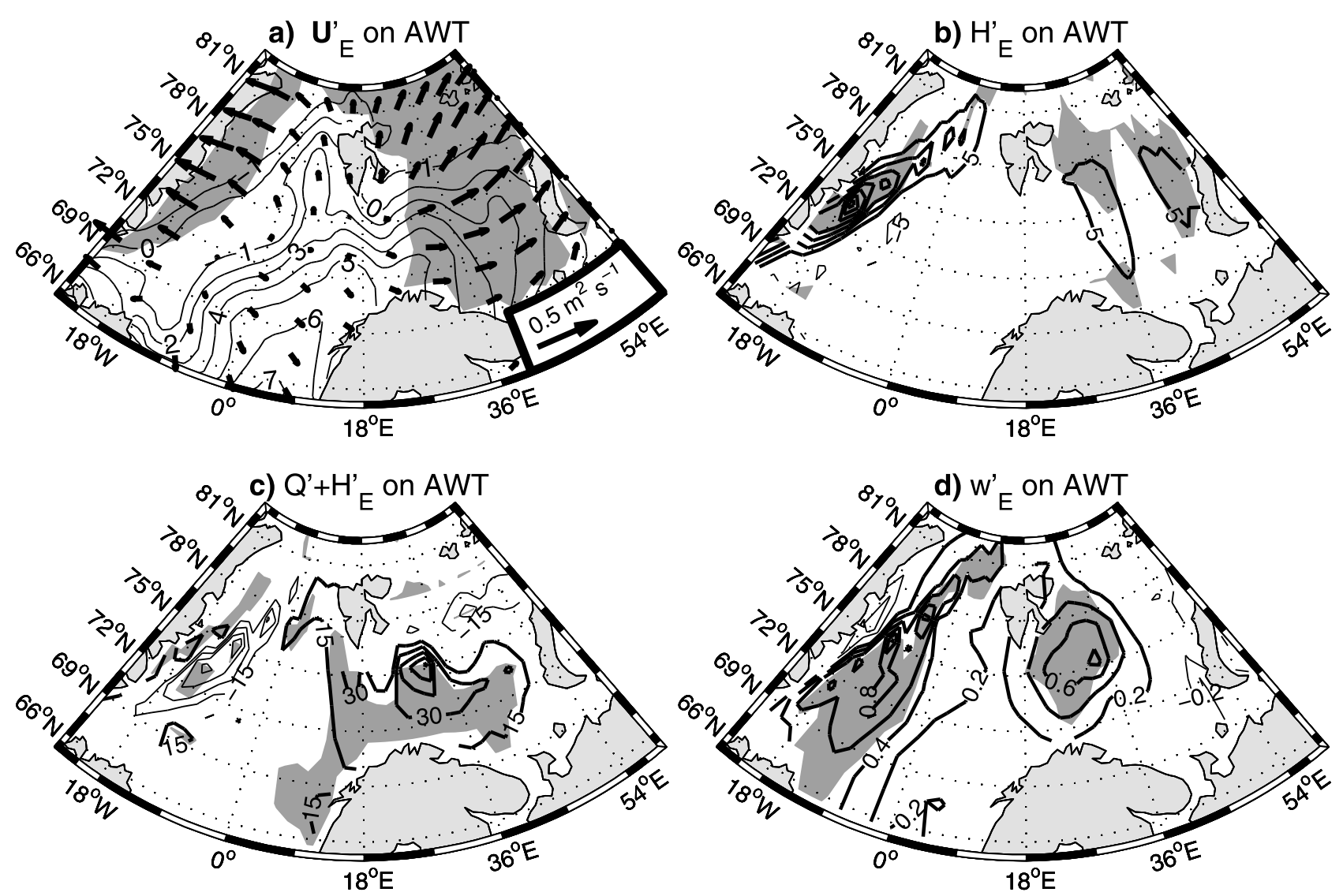

Figure 13. Late winter anomalies of (a) the ocean surface Ekman transport (arrows, in square meters per second per unit AWT index, scaled as in the right-bottom corner), (b) ocean heating due to temperature advection by the Ekman flow, (c) sum of this heating and the total SHF, and (d) ocean surface Ekman suction velocity in the Nordic Seas area in the 1982-2005 period regressed onto the following summer AWT index (Figure 4, circles). In Figure 13a, areas where either the zonal or meridional component of $\mathbf{U}_{E}^{\prime}$ is statistically significant at the $95 \%$ level are shaded while the contours represent the long-term (1982-2005) mean of the late winter SST (in ${ }^{\circ} \mathrm{C}$ ). In Figures $13 \mathrm{~b}-13 \mathrm{~d}$, the contour interval is $5 \mathrm{~W} \mathrm{~m}^{-2}, 15 \mathrm{~W} \mathrm{~m}^{-2}$, and $0.2 \times 10^{-6} \mathrm{~m} \mathrm{~s}^{-1}$ per unit AWT index, respectively, while anomalies statistically significant at the $95 \%$ confidence level are shaded.

where $T_{o}^{\prime}$ and $Q^{\prime}$ are the anomalies of SST and SHF, respectively (see equation (5)), $\partial / \partial t$ is the time derivative, $h$ is the mixed layer depth, $w_{e}$ is the entrainment velocity at which water of temperature $T_{b}$ is entrained into the mixed layer ( $w_{e}=0$ if detrainment), $\mathbf{U}_{g}$ is the geostrophic transport in the mixed layer, and $Q_{r}^{\prime}$ encapsulates all other contributions, such as effects of eddies and small-scale mixing. In the MIZ, $Q_{r}^{\prime}$ should also include a contribution $Q_{i}^{\prime}$ from anomalous melting/freezing processes so that $Q^{\prime}+Q_{i}^{\prime}$ represents the anomalous net heat flux to the ocean from the atmosphere/ice system.

[41] In addition to $Q^{\prime}$, the only term of equation (6) which can directly be calculated from available data is $H_{E}^{\prime}$, that is, the anomaly of heat transport by the Ekman flow (see equation (4)). This term can be written as

$$
H_{E}^{\prime} \approx-\rho_{w} c_{w}\left(\mathbf{U}_{E}^{\prime} \cdot \nabla \bar{T}_{o}+\overline{\mathbf{U}}_{E} \cdot \nabla T_{o}^{\prime}\right),
$$

where the approximate equality sign indicates omission of the term $-\rho_{w} c_{w}\left(\mathbf{U}_{E}^{\prime} \cdot \nabla T_{o}^{\prime}\right)$, found negligible. In the Barents Sea, the Ekman flow generates only small AWT-associated heat anomalies (Figure 13b) which, in the Hopen trench area, contribute less than $10 \%$ to the total late winter warming of $75 \mathrm{~W} \mathrm{~m}^{-2}$ by $Q^{\prime}+H_{E}^{\prime}$ (Figure 13c). These small anomalies arise from the anomalous Ekman transport which is down the gradient of the mean SST (Figure 13a). A larger positive contribution to $H_{E}^{\prime}$ from $-\mathbf{U}_{E}^{\prime} \cdot \nabla \bar{T}_{o}$ appears at the Greenland shelf break where also a substantial warming results from advection of temperature anomalies by the mean Ekman flow $\left(-\overline{\mathbf{U}}_{E} \cdot \nabla T_{o}^{\prime}\right)$. It should be recognized, however, that uncertainties exist on the magnitude of both $Q^{\prime}$ and $H_{E}^{\prime} . H_{E}^{\prime}$ is uncertain in the ice-covered areas as we have assumed that the stress at the ice/ocean interface is the same as the wind stress. Uncertainty in $Q^{\prime}$ results from inexact roughness length formulation in the bulk formulae used in the NCEP/NCAR reanalysis [Renfrew et al., 2002] and from the crude representation of the MIZ in the reanalysis (0 or $100 \%$ for SIC) [Pagowski and Moore, 2001].

[42] During events of positive AWT anomalies, a substantial part of the warming by the SHF anomalies in the Barents Sea open water appears to be balanced by anomalies in the local heat content change, $Q_{T}^{\prime}=\rho_{w} c_{w} \bar{h}\left(\partial T_{o}^{\prime} / \partial t\right)$ on the 
left-hand side of equation (6). In the Hopen trench area, the balance would be roughly exact if a late winter SST change of $0.5^{\circ} \mathrm{C}$ is estimated from the SST anomaly evolution between early winter and spring (Figure $8 \mathrm{~b}$, circles), and the water column in the Hopen trench is considered to be mixed down to the bottom $(350 \mathrm{~m}) \cdot Q^{\prime}{ }_{T}$ would then be $70 \mathrm{~W} \mathrm{~m}^{-2}$ and so would exactly balance $Q^{\prime}$ (Figure 5a). If, however, the local thermal convection is assumed to be limited to $200 \mathrm{~m}$ [Quadfasel et al., 1992] to take into account the existence of a bottom layer originating from haline convection on nearby banks, $Q_{T}^{\prime}$ would be only $40 \mathrm{~W} \mathrm{~m}^{-2}$ and a heat sink of $35 \mathrm{~W} \mathrm{~m} \mathrm{~m}^{-2}$ is needed to compensate for the imbalance between $Q_{T}^{\prime}$ and $Q^{\prime}+H_{E}^{\prime}$. In late winter, when $\bar{T}_{o}$ reaches a minimum (Figure 7a, circles), it is reasonable to assume that the mean SST distribution remains fairly constant (i.e., $Q_{h}^{\prime}=$ $\left.-\rho_{w} c_{w} h^{\prime}\left(\partial \bar{T}_{o} / \partial t\right) \approx 0\right)$ while entrainment in the deep mixed layer should be small [Nilsen and Falck, 2006] (i.e., $Q_{e}^{\prime}=$ $\left.\rho_{w} c_{w}\left[w_{e}\left(T_{b}-T_{o}\right)\right]^{\prime} \approx 0\right)$. The excess heat gained by the mixed layer through air-sea exchanges should therefore be transported through, for example, geostrophic transport anomalies $\left(H_{g}^{\prime}=-\rho_{w} c_{w}\left(\mathbf{U}_{g} \cdot \nabla T_{o}\right)^{\prime}\right)$.

[43] Mixed layer temperature anomalies created in the Hopen trench area (Figure 9d) are indeed likely to be exported westward in the Hopen trench recirculation (HTR in Figure 1a) so that the contribution $-\overline{\mathbf{U}}_{g} \cdot \nabla T_{o}^{\prime}$ should be important. The existence of this topographically guided return flow, which recirculates water from a northern limb of the North Cape current ( $\mathrm{NCaC}$ in Figure 1a), has been confirmed by current measurements between Norway and Bear Island [e.g., Ingvaldsen et al., 2004] (see also section 3.1). The current is also identified with an annual mean velocity of $\sim 5 \mathrm{~cm} \mathrm{~s}^{-1}$ in a pan-Arctic ice-ocean simulation [Maslowski et al., 2004]. Typical barotropic velocities of 5-10 $\mathrm{cm} \mathrm{s}^{-1}$ have been observed in this flow in summer and corroborated by process-oriented numerical modeling [Gawarkiewicz and Plueddemann, 1995]. Combining this value with the estimate of $200 \mathrm{~m}$ for the mixed layer depth and an estimate of the along-flow temperature anomaly gradient of $5 \times 10^{-7}{ }^{\circ} \mathrm{C} \mathrm{m}^{-1}$ (Figure 9d) gives a heat export of $20-40 \mathrm{~W} \mathrm{~m}^{-2}$ close to the difference of $35 \mathrm{~W} \mathrm{~m}^{-2}$ between $Q^{\prime}+H_{E}^{\prime}$ and $Q_{T}^{\prime}$ in the Hopen trench area. Obviously, these are order of magnitude estimates and uncertainty exists not only on the magnitude of the long-term mean velocity but also on the mixed layer depth. Hydrographic data indicate that the mixed layer depth in the Hopen trench area and the Bear Island trough might be considerably larger than $200 \mathrm{~m}$ at the end of the cooling period [Harris et al., 1998]. This is also suggested by the strong coherence of the summer temperature anomalies in the layers above and below $300 \mathrm{~m}$ at the exit from the Barents Sea (Figure 3b).

[44] Anomalous geostrophic flow (i.e., $-\mathbf{U}_{g}^{\prime} \cdot \nabla \bar{T}_{o}$ ) generated, for example, by anomalies in the Ekman suction, may also contribute to exporting heat out of the Hopen trench area. The late winter values of $w_{E}^{\prime}$ reach $0.8 \times 10^{-6} \mathrm{~m} \mathrm{~s}^{-1}$ in the Barents Sea and correlate high $(r=0.78)$ with the AWT anomalies in the Hopen trench area (Figure 13d). These are large anomalies, equal to about one third of the maximum value of $\bar{w}_{E}$ in the Barents Sea. As the adjustment to $w_{E}^{\prime}$ may involve various terms of the barotropic vorticity balance [e.g., Schlichtholz, 2005], any meaningful estimate of $-\mathbf{U}_{g}^{\prime}$. $\nabla \bar{T}_{o}$ cannot be made without current measurements or a dedicated numerical modeling study.
[45] With a current speed of 5-10 $\mathrm{cm} \mathrm{s}^{-1}$, the temperature anomalies formed in the Hopen trench area would be advected to the BSO area within 2-4 months. A gradual westward export of the anomalies formed in the Barents Sea throughout the cooling period can then explain the strong, coherent variability of the summer AWT from the BSO area to Fram strait (Figure 3a, circles). The anomalies transported westward by the Hopen trench recirculation are expected to mix with anomalies traveling eastward in the North Cape current and then with anomalies supplied to the BSO area from the south. However, this mixing should not drastically modify the strong anomalies formed in the Hopen trench area as the temperature anomalies in the Norwegian Atlantic current/North Cape current system depend on the local SHF anomalies that are typically of the same sign as the SHF anomalies in the Hopen trench area (e.g., Figure 13c). The exchanges between the Norwegian Sea and the Barents Sea are dominated by high-frequency currents occurring mainly as wide inflows and outflows in response to local wind fluctuations [Ingvaldsen et al., 2004] and likely contributing to the spatial coherence of the temperature anomalies across the BSO area.

[46] The scenario in which the AWT anomalies observed in the BSO area in summer are formed or ultimately adjusted by anomalous air-sea interactions over the Barents Sea in the presummer seasons does not contradict Skagseth [2008] lagged correlation analysis showing that variations in hydrographic properties of the Atlantic water inflowing to the Barents Sea precede the corresponding variations in the westward outflow. In years when the air-sea heat flux over the Barents Sea is close to average, ocean temperature anomalies may transit around the western Barents Sea without being substantially altered by surface interactions. Moreover, the time lag of $\sim 7$ months obtained by Skagseth [2008] between the 300-450 m layer in the outflow zone and the near-surface $(50-200 \mathrm{~m})$ layer of the inflow zone may reflect the deepening of the mixed layer depth during the cooling period rather than the transit time of the anomalies around the western Barents Sea. The lag is indeed reduced to $\sim 3$ months when the outflow is sampled over shallower isobaths.

\subsection{Anomalous Late Winter Air-Sea Interactions}

[47] As discussed in section 3.3, the AWT-associated late winter SHF anomalies over the Barents Sea open water are generated by the concomitant SAT and SHUM anomalies (Figures 9a and 9b). In the case of the sensible SHF, the anomalies include adjustment of the SST to the anomalous total heat flux. In the Hopen trench area, the SAT and SHUM anomalies should arise from anomalous temperature and humidity advection. Off the ice edge, a $1 \mathrm{~m} \mathrm{~s}^{-1}$ anomaly of the surface wind is down a mean temperature gradient of $\sim 10^{\circ} \mathrm{C} / 250 \mathrm{~km}$ (Figure $12 \mathrm{a}$ ) and humidity gradient of $\sim 1 \mathrm{~g} \mathrm{~kg}^{-1} / 200 \mathrm{~km}$ (Figure $12 \mathrm{~b}$, contours). For a typical $1 \mathrm{~km}$-thick boundary layer, anomalous sensible and latent heat flux convergences of $\sim 50 \mathrm{~W} \mathrm{~m}^{-2}$ and $\sim 15 \mathrm{~W} \mathrm{~m}^{-2}$ are obtained, respectively. These crude estimates fit well with the actual values of the AWT-associated downward sensible and latent SHF anomalies in the Hopen trench area (Table 2). Since the anomalous winds blow across the SAT and SHUM front also north of the ice edge, advective 

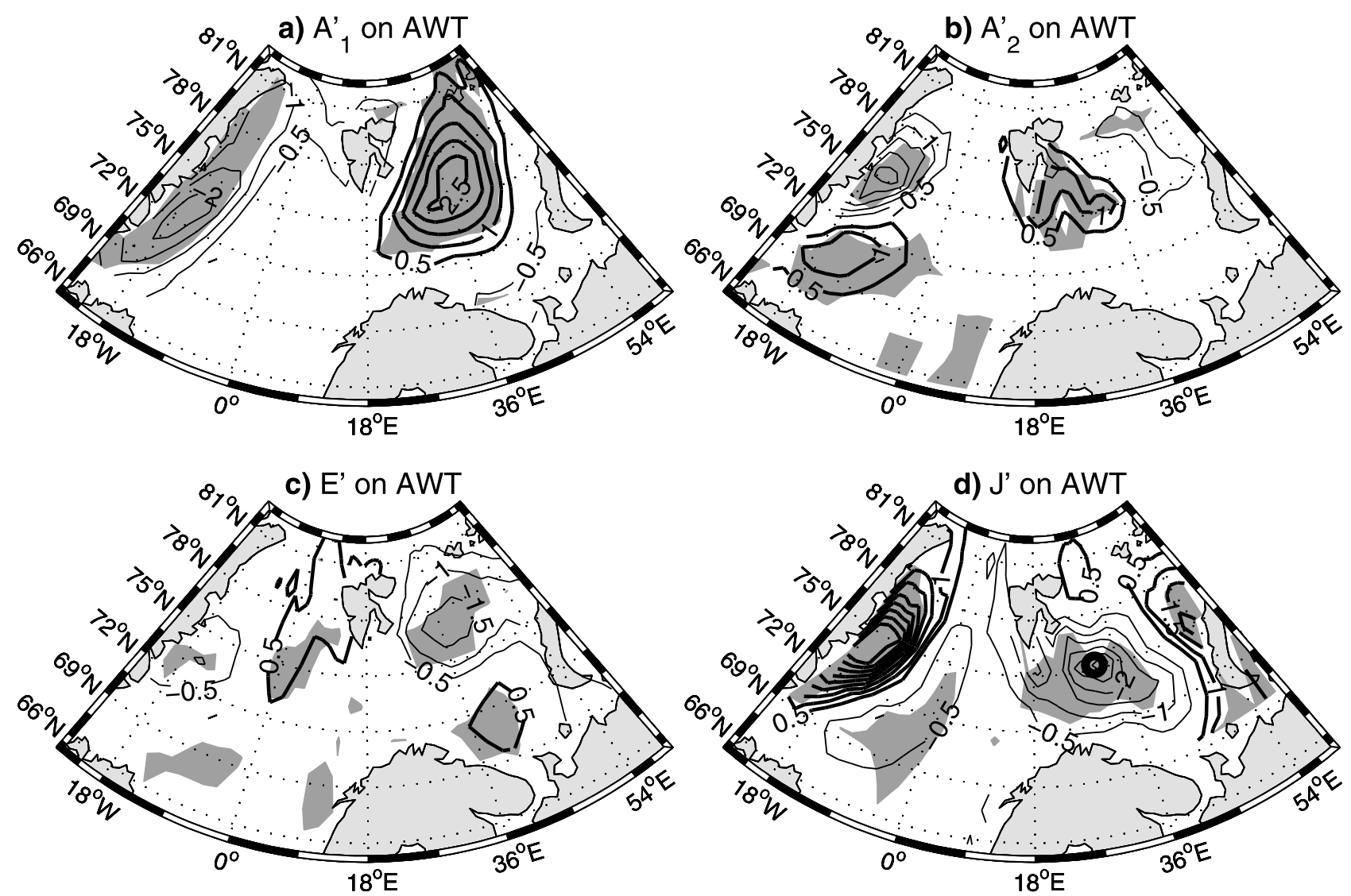

Figure 14. Late winter anomalies on the right-hand side of equation (8): (a) $A_{1}^{\prime}=-\mathbf{u}_{a}^{\prime} \cdot \nabla \bar{T}_{a}$, (b) $A_{2}^{\prime}=-\overline{\mathbf{u}}_{a}$ $\cdot \nabla T_{a}^{\prime}$, (c) $E^{\prime}=-\left(\nabla \cdot \overline{\overline{\mathbf{u}_{a}^{\prime \prime} T_{a}^{\prime \prime}}}\right)^{\prime}$, and (d) $J^{\prime}=-\left(A_{1}^{\prime}+A_{2}^{\prime}+E^{\prime}\right)$ in the Nordic Seas area in the 1982-2005 period regressed onto the following summer AWT index (Figure 4, circles). The contour interval is $0.5^{\circ} \mathrm{C} \mathrm{d}^{-1}$ per unit AWT index. Dark shading denotes anomalies statistically significant at the $95 \%$ confidence level. In Figure $14 \mathrm{~d}$, the circle indicates the location of the largest AWT-associated downward SHF anomaly (circle in Figure 5a).

warming and moistening should also contribute to the positive SAT and SHUM anomalies over the Barents Sea MIZ.

[48] To examine in more detail the importance of largescale wind anomalies compared with other contributions (advection of temperature anomalies, eddy heat fluxes) in controlling the heat balance of the atmospheric boundary layer, the thermodynamic equation is written as follows:

$$
0 \approx \frac{\partial T_{a}^{\prime}}{\partial t}=-\underbrace{\mathbf{u}_{a}^{\prime} \cdot \nabla \bar{T}_{a}}_{A_{1}^{\prime}}-\underbrace{\overline{\mathbf{u}}_{a} \cdot \nabla T_{a}^{\prime}}_{A_{2}^{\prime}}+E^{\prime}+J^{\prime},
$$

in which the contribution $-\mathbf{u}_{a}^{\prime} \cdot \nabla T_{a}^{\prime}$ has been neglected and vertical advection has been omitted as only the surface heat balance is considered. In equation (8), $E^{\prime}$ is the anomaly of the eddy heat flux convergence defined in equation (2) and $J$ is the diabatic heating anomaly here estimated as residual of other terms. The advection terms on the right-hand side of equation (8), $A_{1}^{\prime}=-\mathbf{u}^{\prime} \cdot \nabla \bar{T}_{a}$ and $A_{2}^{\prime}=-\overline{\mathbf{u}}_{a} \cdot \nabla T_{a}^{\prime}$, obtained from equation (1), represent advection of the mean SAT by anomalous winds and advection of SAT anomalies by the mean winds, respectively. The anomalous SAT tendency $\left(\partial T_{a}^{\prime} / \partial t\right)$ is negligible compared to other terms but is retained on the left-hand side of equation (8) to emphasize the fact that the terms on the right-hand side represent competitive warming and cooling sources. The AWT-associated late winter distributions of these terms over the Nordic Seas are shown in Figure 14. Although the residual $J^{\prime}$ is expected to contain computational errors, these should not be too large as its overall distribution (Figure 14d) is consistent with the distribution of the SHF anomalies (Figure 5a). An equation similar to equation (8) has been derived for SHUM anomalies. The distributions of the different contributions (not shown) mirror the corresponding distributions for the SAT and therefore are not discussed.

[49] The anomalous atmospheric circulation generates a warming over most of the Barents Sea, with a maximum $\left(\sim 3^{\circ} \mathrm{C} \mathrm{d}^{-1}\right)$ near the Hopen trench area (Figure 14a). The mean winds over the northern Barents Sea advect the SAT anomalies southwestward (Figure 9a), reducing the warming over the northeastern Barents Sea and enhancing it southeast of Svalbard (Figure 14b). As a result, anomalous heat advection is extreme $\left(\sim 4^{\circ} \mathrm{C} \mathrm{d}^{-1}\right)$ in the Hopen trench area (at the circle in Figure 14d) where its correlation with the AWT index reaches 0.83 (Table 1). There, it is mainly compensated by diabatic cooling (Figure 14d). The eddy heat fluxes play a less important role in the Hopen trench area but are 
responsible for a major atmospheric cooling $\left(\sim 2^{\circ} \mathrm{C} \mathrm{d}^{-1}\right)$ slightly north of it (Figure 14c).

\section{Link of AWT Variability to Variability in the MIZs}

\subsection{Late Winter Anomalies}

[50] As mentioned in section 3.2, a scenario in which the primary reason for the retreat of the late winter MIZ areas during warm AWT events (Figure 9c) would be enhanced surface sea ice melting would not support upward SHF anomalies found in the MIZs (Figure 5a). Basal ice melt by the ocean mixed layer or dynamic ice removal must therefore be a major contribution to the upward SHF anomalies in the MIZs. The latter indeed plays an important role according to the distribution of the wind anomalies. During warm AWT events in the BSO area, the southerly to easterly wind anomalies in the Barents Sea MIZ (Figure 12a) result in a northeastward to northwestward ice edge retreat. In the Greenland Sea MIZ, enhanced northerlies (Figure 12a) lead to a transport of ice onto the Greenland shelf, which ultimately is, at least partly, melted $\left(Q_{i}^{\prime}<0\right)$ by the additional heat injected to the ocean mixed layer/ice system by the atmospheric forcing $\left(Q^{\prime}+H_{E}^{\prime}\right)$ (Figure 13c). Off the shelf, the export of ice corresponding to a reduction in sea ice melt $\left(Q_{i}^{\prime}>0\right)$ is responsible for the large increase of the ocean heat loss to the atmosphere. Assuming the approximate balance $Q^{\prime}+H_{E}^{\prime} \approx-Q_{i}^{\prime}$, an anomalous ice export of $\sim 60 \mathrm{~km}^{3}$ month $^{-1}$ would be needed to account for the late winter integral of $Q^{\prime}+H_{E}^{\prime}$ over the Greenland Sea MIZ $(\sim 8 \mathrm{TW})$. This corresponds to an average reduction of $\sim 0.5 \mathrm{~cm} \mathrm{~d}^{-1}$ in sea ice melt, about one-half of the winter ice melt rate expected in this area [e.g., Houssais and Hibler III, 1993; Bitz et al., 2005].

[51] All over the Greenland Sea MIZ, the anomalous northerlies generate a cooling which reaches a maximum of $\sim 2^{\circ} \mathrm{C} \mathrm{d}^{-1}$ in the southwestern Greenland Sea (Figure 14a) where a half as large cooling is also due to anomalous eddy heat flux divergence (Figure 14c). Therefore, the positive SAT anomalies in the Greenland Sea MIZ (Figure 9a, contours) must originate from the excess sensible heat loss from the ocean triggered by the wind-driven ice edge retreat. In the open water, advection of SAT anomalies by the mean winds is the only substantial source of warming over the Iceland Sea (Figure 14b), while over the eastern Greenland Sea warming is due to anomalous eddy heat flux convergence (Figure 14c). Still, these heat sources are relatively small so that, in agreement with the distribution of the SHF anomalies (Figure 5a), the diabatic cooling over the open Greenland Sea is much smaller $\left(<1^{\circ} \mathrm{C} \mathrm{d}^{-1}\right)$ than the large diabatic warming $\left(\sim 5^{\circ} \mathrm{C} \mathrm{d}^{-1}\right)$ in the MIZ (Figure 14d). Similarly, advection of dry air by enhanced northerlies over the western side of the Nordic Seas and drying by anomalous moisture flux divergence (not shown) act against the formation of positive SHUM anomalies observed in the Greenland Sea MIZ (Figure 9b) so that these anomalies must represent a response to anomalous surface humidity fluxes induced by wind-driven SIC changes. In contrast to the Greenland Sea MIZ, the anomalous warm air advection over the Barents Sea tends to reinforce the effect of the dynamic ice removal on the surface atmospheric warming (Figure 14a). As a consequence of this contrast between cold (and dry) advection over the Greenland Sea and warm (and moist) advection over the Barents Sea, larger SAT (and SHUM) anomalies are found in the Barents Sea MIZ (Figures 9a and 9b) despite weaker SHF anomalies (Figure 5a).

\subsection{Presummer Evolution}

[52] The large late winter SAT anomalies in the Greenland Sea and Barents Sea MIZs (Figure 9a) are correlated with the AWT index nearly as well as the corresponding anomalies over the Barents Sea open water (at the location of maximum anomalies, $r \approx 0.75$ ). The high correlations encountered on the eastern and western sides of the Nordic Sea MIZ suggest that the AWT-associated atmospheric variability is coherent between the two regions. However, the presummer evolution of the correlations for the SAT anomalies indicates that an intraseasonal shift may exist between the variability in these regions (Figure 10c). In the Greenland Sea, late winter corresponds to the peak of the correlations (squares) while in the Barents Sea, peak correlations occur in early spring (circles). In both cases, the peaks are in phase with the minimum of the MIZ area (for positive AWT events in the BSO area) (Figure 15a). On the other hand, the largest SAT anomalies occur simultaneously over both MIZs (Figure 15b) and in concert with extreme anomalies of regional winds expressed by the OIW index (Figure 10b, circles). Still, the wind forcing has a different timing in the two regions: while the anomalous southerlies over the Barents Sea MIZ are the strongest in late winter (Figure 15c, circles), the anomalous northerlies over the Greenland Sea MIZ are extreme already in early winter (lag -7 months; Figure 15c, squares).

[53] The timing of the extreme AWT-associated wind forcing on the western side of the Nordic Seas may be related to the NAO, as suggested by a substantial impact of the NAO on the wind anomalies along the Greenland coast (Figure 12b). The correlation of the pattern-based NAO index with the summer AWT anomalies in the BSO area is indeed the highest in early winter (Figure 10b, squares). The 2 month delay of the peak response of sea ice and air temperature in the Greenland Sea MIZ (Figures 15a and $15 \mathrm{~b}$, squares) to the extreme wind forcing (Figure 15c, squares) should result from oceanic feedbacks related, for example, to entrainment of warm water from below the mixed layer. The onshore ice export by the anomalous northerlies (Figure 12a) indeed favors thermal convection in ice-freed areas so that the warm, subsurface Atlantic water supplied to the Greenland Sea MIZ by the return Atlantic current (RAC in Figure 1a) can be entrained into the deepening mixed layer and reinforce the ice edge retreat and, consequently, the surface atmospheric warming. Anomalous geostrophic flow may contribute to this process through local mass convergence or divergence in the mixed layer modifying the entrainment velocity or through anomalous heat transport within the mixed layer itself. Anomalous geostrophic flow is indeed expected to occur in response to the Ekman suction anomalies, which in the Greenland Sea are even stronger than in the Barents Sea and show maxima just in the MIZ (Figure 13d).

[54] In the Barents Sea MIZ, the simultaneous peaks in the wind forcing and the SAT anomalies (Figures $15 \mathrm{~b}$ and 15c, circles) are consistent with a substantial contribution of 

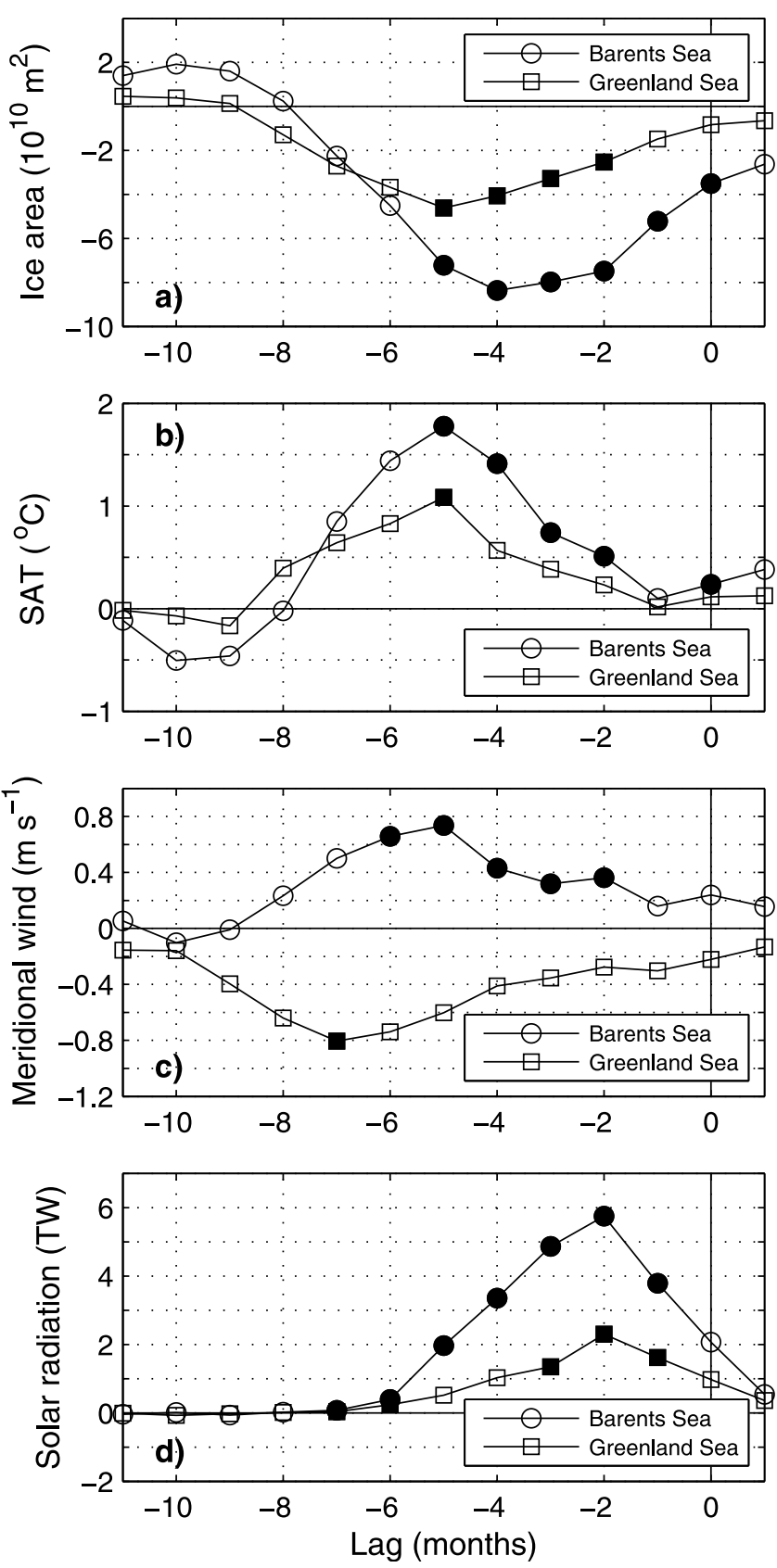

Figure 15. Time-lagged regression coefficients of the anomalies of (a) SIC integrated over the eastern (circles) and western (squares) sides of the Nordic Seas, (b) SAT and (c) meridional wind velocity (positive southerly) averaged over the eastern (circles) and western (squares) climatological MIZs, and (d) net shortwave radiative SHF (positive downward) integrated over the eastern (circles) and western (squares) climatological MIZs regressed onto the summer AWT index in the 1982-2005 period (Figure 4, circles). In Figure 15a-15d, units are tens of billions square meters, degrees Celsius, meters per second, and terawatts per unit AWT index, respectively. Filled symbols denote anomalies statistically significant at the $95 \%$ confidence level. atmospheric heat advection to these anomalies (Figure 14a). The 1 month delayed occurrence of the extreme sea ice response (Figure 15a, circles) to the wind forcing in this region may be related to an oceanic transport of heat anomalies across the MIZ. Such a transport would also be consistent with the 1 month delay between the maximum of the SAT anomalies (Figure 15b, circles) and their peak correlation with the AWT index (Figure 10c, circles).

[55] In the Barents Sea, large SIC anomalies persist until late spring (lag -2 months; Figure 15a, circles) when their correlation with the AWT index is the highest (local extremum of -0.87 , see Table 1). A similar persistence of the SIC or SST anomalies associated with a shift between the maximum of the anomalies and their peak correlations with the AWT index is also observed in the Greenland Sea MIZ. The SST anomalies there are the largest in late winter (Figure 8b, diamonds) but show the highest correlations with the AWT index in spring (local extremum of 0.75, not shown). The persistence of SIC and SST anomalies in the MIZ would be consistent with the existence of a positive icealbedo feedback enhancing SIC anomalies as a result of absorption of solar radiation in the ocean at the advent of the warm season [e.g., Maykut and Perovich, 1987]. A peak correlation of 0.74 between the net solar radiation averaged over the entire Nordic Sea MIZ and the AWT index is indeed found in late spring when anomalies of this radiation are the strongest in the MIZs on both sides of the Nordic Seas (Figure 15d).

\section{Summary and Conclusions}

[56] Heat anomalies streaming toward the Arctic Ocean in the West Spitsbergen current are often attributed to an NAO-controlled variability of the Atlantic water inflow across the Greenland-Scotland ridge and a downstream modification by air-sea interactions over the Norwegian Sea [Dickson et al., 2000; Furevik and Nilsen, 2005]. To propose a different or complementing scenario, we have constructed a time series of summer (June-September) temperature anomalies in the Atlantic water core (AWT anomalies) upstream of the Norwagian Atlantic current for the period 1982-2005 using 1900 hydrographic stations from the BSO area (box in Figure 1) where the northward flow can interact with the Barents Sea circulation. A composite analysis of summer subsurface ocean temperature carried out over a broader area for "BSO warm summers" and "BSO cold summers" has indicated a stronger link of the AWT anomalies in the BSO area to the concomitant ocean temperature anomalies in the Barents Sea than to the concomitant and 1 year earlier AWT anomalies in the Norwegian Atlantic current. We have then shown, using surface gridded fields from the NCEP/NCAR reanalysis and the Reynolds SST data, that the summer AWT anomalies in the BSO area can to a large extent be driven by air-sea interactions over the Barents Sea in presummer seasons, with a peak atmospheric forcing occurring in late winter (January-April) and a peak ocean response occurring in spring (March-June). These interactions are not significantly related to the concomitant NAO variability. A weak but significant link of the summer AWT anomalies in the BSO area to the previous winter NAO index is rather an expression of a regional teleconnection to atmospheric variability over the Greenland Sea. 


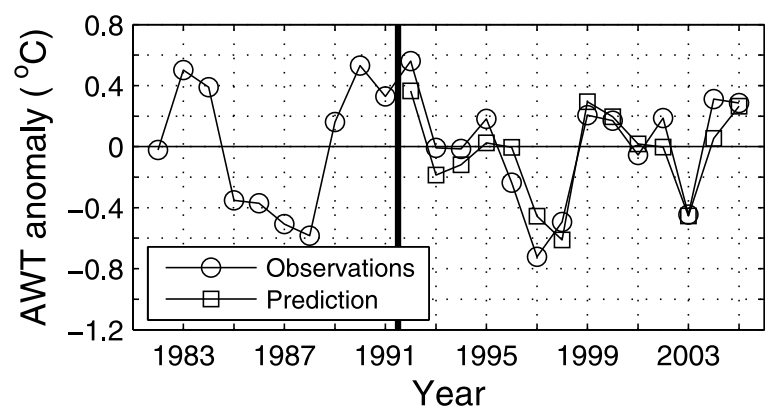

Figure 16. Summer AWT anomalies in the 1982-2005 period (circles), redrawn from Figure 2c, and their seasonal prediction for the 1992-2005 subperiod (squares) from the late winter OIW index (Figure $4 \mathrm{~b}$, squares to the right of the bold vertical line). The prediction is based on a linear model of the relationship between the two variables fitted to the data from the 1982-1991 subperiod.

[57] According to our results, warm and moist advection by anomalous late winter on-ice winds induces downward turbulent SHF anomalies over the Barents Sea open water, especially large ( $70 \mathrm{~W} \mathrm{~m}^{-2}$ per a typical AWT anomaly) at the ice edge in the Hopen trench area (circle in Figure 1b). A half of the downward SHF anomaly in this area is balanced by local warming of the ocean mixed layer while the other half is most likely exported by the mean geostrophic flow. Modification of this balance by anomalies in the Ekman transport is minor but anomalous geostrophic advection triggered by strong anomalies in the Ekman suction may play a role. Similarly, cold and dry advection by anomalous off-ice winds induces upward SHF anomalies over the Barents Sea open water and subsequent oceanic cooling. Once formed, temperature anomalies from the Barents Sea should be transmitted westward by the Hopen trench recirculation of the North Cape current (HTR in Figure 1a). This scenario does not exclude other mechanisms that could contribute to the AWT anomalies observed in the West Spitsbergen current. In particular, anomalous geostrophic velocities could be generated by the same regional pattern of wind anomalies which is responsible for the anomalous airsea heat flux over the Barents Sea open water. A secondary maximum at $10^{\circ} \mathrm{E}$ in the distribution of the subsurface ocean temperature anomalies along $74^{\circ} \mathrm{N}$ (Figure $3 \mathrm{~b}$ ) indeed suggests that velocity anomalies in the baroclinic jet along the Arctic front may play a role.

[58] The correlations summarized in Table 1 indicate that the anomalous air-sea interactions over the Barents Sea open water can explain $\sim 80 \%$ of the variance of the summer heat anomalies in the BSO area. This is huge compared to $\sim 30 \%$ of the AWT variance explained by the NAO. This finding may not only be of importance for understanding interannual Arctic climate variability but also have practical consequences. For instance, the quality of statistical prediction tools developed for the regional fisheries management [Ottersen et al., 2000] may benefit from inclusion of some variables listed in Table 1 . One of these variables is the OIW index which has been introduced in the present study as a simple measure of the strength of the air flow across the Barents Sea ice edge. As a simple example, Figure 16 compares the summer AWT anomalies (circles) with their seasonal prediction in the 1992-2005 period (squares) from the late winter OIW index (Figure 4b, squares) based on a linear model "trained" on the data from the preceding decade (1982-1991). The correlation skill score (0.89), proportion of explained variance $(79 \%)$, and mean-squared error $\left(0.02^{\circ} \mathrm{C}^{2}\right)$ of the prediction are indeed promising. This also shows that uncertainty in the AWT series is lower than indicated by the formal error bars (Figure 2b).

[59] We have also demonstrated that the AWT-associated late winter wind anomalies generate heat and moisture anomalies having the same sign over the entire Nordic Seas but the largest magnitude in the Barents Sea and Greenland Sea MIZs. These anomalies coexist with a dipole pattern of turbulent SHF anomalies which has lobes of opposite sign over the open ocean and in the MIZs. The pattern is similar to the SHF distribution associated with wintertime Arctic sea ice anomalies [Deser et al., 2000]. A detailed analysis has shown that when the anomalous on-ice winds induce downward SHF anomalies over the Barents Sea open water, a simultaneous ice reduction magnifies the advective SAT and SHUM anomalies in the nearby MIZ through generation of anomalous upward sensible heat and moisture fluxes. A concomitant ice removal by northerly wind anomalies creates a western lobe of the upward SHF anomalies in the Greenland Sea MIZ that is twice as strong as the lobe in the Brents Sea MIZ even though the SAT and SHUM anomalies are stronger over the Barents Sea MIZ. In contrast, the western downward lobe of the SHF anomalies at the ice edge, driven by anomalous eddy heat and moisture flux convergence and by advection of the warm SAT and moist SHUM anomalies from the MIZ by the mean northerlies, is relatively weak. These east-west differences are due to a contrast between advection by the anomalous winds, which is cold and dry over the Greenland Sea when it is warm and moist over the Barents Sea.

[60] Another east-west difference that has been noted but not explained here is a 2 month delay of the extreme AWTassociated wind forcing over the Barents Sea with regard to the corresponding forcing over the Greenland Sea. If the delay reflects a casual phenomenon, it may involve a panArctic teleconnection, as suggested by a link of wintertime sea ice anomalies in the Barents Sea to synoptic activity over the Arctic Ocean [Sorteberg and Kvingedal, 2006]. Alternatively, the delay may be an expression of a regional oceanic bridge. Local changes in ocean circulation induced by large Ekman suction anomalies in the Greenland Sea (Figure 13d) may influence the circulation and heat fluxes in the Barents Sea and consequently affect the atmospheric circulation in this area through a self-sustaining feedback. Existence of such a feedback is suggested, for example, by a numerical simulation of the early 20th-century warming in the Arctic [Bengtsson et al., 2004].

\section{Appendix A}

[61] To assess the statistical significance of the correlations between the AWT index (Figure 4, circles) and other indices of regional or large-scale climate variability and between the different indices and the anomalies of surface fields, the probability $(p)$ that the correlations could be produced by random noise is estimated using a two-tailed Students's $t$ test. The test is carried out using an effective 
number of degrees of freedom $\left(N_{\text {eff }}\right)$ to account for the serial correlation due to low-frequency oscillations. The calculation of $N_{\text {eff }}$ is based on a technique introduced by Davis [1976] that, for discrete data with a 1 year interval, yields the following formula:

$$
N_{\mathrm{eff}}=N\left[1+2 \sum_{i=1}^{i=N-1} r_{a i} r_{b i}\right]^{-1},
$$

where $N$ is the length of the time series (typically 24 in our case) while $r_{a i}$ and $r_{b i}$ are the autocorrelations of the first and second series, respectively, at the lag of $i$ years. To discriminate unreliable autocorrelations at large lags, the biased estimators of $r_{a i}$ and $r_{b i}$ are used. For the highest correlations of surface variables with the AWT index (summarized in Table 1), the $p$ values are very small (high confidence levels) even though $N_{\text {eff }}$ is reduced by a half compared to the nominal number of degrees of freedom $(N-2)$ accurate for the time series that are not serially correlated.

[62] The statistical significance of the AWT trend (Figure 2b, dashed line) is estimated using a one-tailed Students's $t$ test. Following Santer et al. [2000], $N_{\text {eff }}$ for this test $(\sim 10)$ is obtained from a formula based on the lag-1 autocorrelation of the regression residuals, which is 0.4 for the AWT time series (Figure $2 \mathrm{~b}$, circles). The test shows that the AWT trend is significant only at a low (90\%) confidence level.

[63] Acknowledgments. The hydrographic data were provided by the International Council for the Exploration of the Sea (http://www.ices. $\mathrm{dk} /$ ) and the National Oceanographic Data Center of NOAA, U.S. (http:// www.nodc.noaa.gov/). The NOAA-CIRES ESRL/PSD Climate Diagnostics branch is acknowledged for providing the NCEP/NCAR reanalysis and the Optimum Interpolation (OI2) SST/SIC product (http://www.cdc. noaa.gov/). The station-based NAO index was obtained from the Climate and Global Dynamics division of NCAR (http://www.cgd.ucar.edu/cas/ jhurrell/).

\section{References}

Bengtsson, L., V. A. Semenov, and O. M. Johannessen (2004), The early twentieth-century warming in the Arctic: A possible mechanism, J. Clim., 17, 4045-4057.

Bitz, C. M., M. M. Holland, E. C. Hunke, and R. E. Moritz (2005), On the maintainence of sea-ice edge, J. Clim., 18, 2903-2921.

Blindheim, J., V. Borovkov, B. Hansen, S.-A. Malmberg, W. R. Turrell, and S. Østerhus (2000), Upper layer cooling and freshenning in the Norwegian Sea in the relation to atmospheric forcing, Deep Sea Res. Part I, 47, 655-680.

Boyer, T. P., J. I. Antonov, H. E. Garcia, D. R. Johnson, R. A. Locarnini, A. V. Mishonov, M. T. Pitcher, O. K. Baranova, and I. V. Smolyar (2006), World Ocean Database 2005 [DVDs], NOAA Atlas NESDIS, vol. 60, edited by S. Levitus, 190 pp., U.S. Govt. Print. Off., Washington, D. C.

Davis, R. E. (1976), Predictability of sea surface temperature and sea level pressure anomalies over the North Pacific Ocean, J. Phys. Oceanogr., 6 , 249-266.

Deser, C., J. E. Walsh, and M. S. Timlin (2000), Arctic sea ice variability in the context of recent atmospheric circulation trends, J. Clim., 13, 617-633.

Dickson, R. R., J. Meincke, I. Vassie, J. Jungclauss, and S. Østerhus (1999), Possible predictability in overflow from the Denmark Strait, Nature, 397, 243-246.

Dickson, R. R., T. J. Osborn, J. W. Hurrell, J. Meincke, J. Blindheim, B. Ådlandsvik, T. Vinje, G. Alekseev, and W. Maslowski (2000), The Arctic Ocean response to the North Atlantic Oscillation, J. Clim., 13, 2671-2696.

Frankignoul, C. (1985), Sea surface temperature anomalies, planetary waves and air-sea feedback in the middle latitudes, Rev. Geophys., 23, 357-390.

Frankignoul, C., A. Czaja, and B. L'Heveder (1998), Air-sea feedback in the North Atlantic and surface boundary conditions for ocean models, J. Clim., 11, 2310-2324.
Furevik, T. (2001), Annual and interannual variability of Atlantic Water temperatures in the Norwegian and Barents Seas, Deep Sea Res. Part I, $48,383-404$.

Furevik, T., and J. E. Ø. Nilsen (2005), Large-scale atmospheric circulation variability and its impacts on the Nordic Seas ocean climate: A review, in The Nordic Seas: An Integrated Perspective: Oceanography, climatology, Biogeochemistry, and Modeling, Geophys. Monogr. Ser., vol. 158, edited by H. Drange et al., pp. 105-136, AGU, Washington, D. C.

Gascard, J.-C., A. J. Watson, K. A. O. M.-J. Messias, T. Johannessen, and K. Simonsen (2002), Long-lived vortices as a mode of deep ventilation in the Greenland Sea, Nature, 416, 525-527.

Gawarkiewicz, G., and A. J. Plueddemann (1995), Topographic control of thermohaline front structure in the Barents Sea Polar Front on the south flank of Spitsbergen Bank, J. Geophys. Res., 100, 4509-4524.

Harris, C. L., A. J. Plueddemann, and G. Gawarkiewicz (1998), Water mass distribution and polar front structure in the western Barents Sea, J. Geophys. Res., 103, 2905-2917.

Hátún, H., A. B. Sand, H. Drange, B. Hansen, and H. Valdimarsson (2005), Influence of the Atlantic Subpolar Gyre on the thermohaline circulation, Science, 309, 1841-1844.

Herbaut, C., and M.-N. Houssais (2009), Response of the eastern North Atlantic subpolar gyre to the North Atlantic Oscillation, Geophys. Res. Lett., 36, L17607, doi:10.1029/2009GL039090.

Houssais, M.-N., and W. D. Hibler III (1993), Importance of convective mixing in seasonal ice margin simulations, J. Geophys. Res., 98, $166,427-16,448$.

Hurrell, J. W. (1995), Decadal trends in the North Atlantic Oscillation: Regional temperature and precipitation, Science, 269, 676-679.

Hurrell, J. W., Y. Kushnir, G. Ottersen, and M. Visbeck (2003), An overview of the North Atlantic Oscillation, in The North Atlantic Oscillation: Climate Significance and Environmental Impact, Geophys. Monogr. Ser. vol. 134, edited by J. W. Jurrell et al., pp. 1-35, AGU, Washington, D. C.

Ingvaldsen, R. B., L. Asplin, and H. Loeng (2004), Velocity field of the western entrance to the Barents Sea, J. Geophys. Res., 109, C03021, doi:10.1029/2003JC001811.

International Council for the Exploration of the Sea (2006), Hydrographic Database, http://www.ices.dk/ocean/aspx/HydChem/HydChem.aspx, Int. Counc. for the Explor. of the Sea, Copenhagen.

Johannessen, O. M., et al. (2004), Arctic climate change: Observed and modelled temperature and sea-ice variability, Tellus Ser. A, 56, 328-341.

Kalnay, E., et al. (1996), The NCEP/NCAR 40-yr reanalysis project, Bull. Am. Meteorol. Soc., 77, 437-471.

Karcher, M. J., R. Gerdes, F. Kauker, and C. Köberle (2003), Arctic warming: Evolution and spreading of the $1990 \mathrm{~s}$ warm event in the Nordic seas and the Arctic Ocean, J. Geophys. Res., 108(C2), 3034, doi:10.1029/ 2001JC001265.

Levitus, S., J. Antonov, and T. Boyer (2005), Warming of the world ocean, 1955-2003, Geophys. Res. Lett., 32, L02604, doi:10.1029 2004GL021592.

Maslowski, W., D. Marble, W. Walczowski, U. Schauer, J. L. Clement, and A. J. Semtner (2004), On climatological mass, heat, and salt transports through the Barents Sea and Fram Strait from a pan-Arctic coupled iceocea model simulation, J. Geophys. Res., 109, C03032, doi:10.1029/ 2001JC001039.

Mauritzen, C. (1996), Production of dense overflow waters feeding the North Atlantic across the Greenland-Scotland Ridge. Part 1: Evidence of a revised circulation scheme, Deep Sea Res. Part I, 43, 769-806.

Maykut, G. A., and D. K. Perovich (1987), The role of shortwave radiation in the summer decay of sea ice cover, J. Geophys. Res., 92, 7032-7044.

Nilsen, J. E. Ø., and E. Falck (2006), Variations of mixed layer properties in the Norwegian Sea for the period 1948-1999, Prog. Oceanogr., 70, 58-90.

Nilsen, J. E. Ø., Y. Gao, H. Drange, T. Furevik, and M. Bentsen (2003), Simulated North Atlantic-Nordic Seas water mass exchanges in an isopycnic coordinate OGCM, Geophys. Res. Lett., 30(10), 1536, doi:10.1029/ 2002GL016597.

Orvik, K. A., and P. Niiler (2002), Major pathways of Atlantic water in the northern North Atlantic and Nordic Seas toward Arctic, Geophys. Res Lett., 29(19), 1896, doi:10.1029/2002GL015002.

Orvik, K. A., and Ø. Skagseth (2005), Heat flux variations in the eastern Norwegian Atlantic Current toward the Arctic from moored instruments, 1995-2005, Geophys. Res. Lett., 32, L14610, doi:10.1029/ 2005 GL023487.

Østerhus, S., W. R. Turrell, S. Jónsson, and B. Hansen (2005), Measured volume, heat, and salt fluxes from the Atlantic to the Arctic Mediterranean, Geophys. Res. Lett., 32, L07603, doi:10.1029/2004GL022188.

Ottersen, G., B. Ådlandsvik, and H. Loeng (2000), Predicting the temperature in the Barents Sea, Fish. Oceanogr., 9, 121-135. 
Pagowski, M., and G. W. K. Moore (2001), A numerical study of an extreme cold-air outbreak over the Labrador Sea: Sea ice, air-sea interaction, and development of polar lows, Mon. Weather Rev., 129, 47-72.

Polyakov, I. V., L. A. Timokhov, U. S. Bhatt, R. L. Colony, H. L. Simmons, D. Walsh, J. E. Walsh, and V. F. Zakharov (2004), Variability of the intermediate Atlantic water of the Arctic Ocean over the last 100 years, J. Clim., 17, 4485-4497.

Polyakov, I. V., U. S. Bhatt, H. L. Simmons, D. Walsh, J. E. Walsh, and $X$. Zhang (2005a), Multidecadal variability of North Atlantic temperature and salinity during the 20th century, J. Clim., 18, 4562-4581.

Polyakov, I. V., et al. (2005b), One more step toward a warmer Arctic, Geophys. Res. Lett., 32, L17605, doi:10.1029/2005GL023740.

Quadfasel, D., B. Rudels, and S. Selchow (1992), The Central Bank vortex in the Barents Sea: Watermass transformation and circulation, ICES Mar. Sci. Symp., 195, 40-51.

Renfrew, I. A., G. W. K. Moore, P. S. Guest, and K. Bumke (2002), A comparison of surface layer and surface turbulent flux observations over the Labrador Sea with ECMWF analyses and NCEP reanalyses, J. Phys. Oceanogr., 32, 383-400.

Reynolds, R. W., N. A. Rayner, T. M. Smith, D. C. Stokes, and W. Wang (2002), An improved in situ and satellite SST analysis for climate, J. Clim., 15, 1609-1625.

Saloranta, T. M., and P. M. Haugan (2001), Interannual variability in the hydrography of Atlantic water northwest of Svalbard, J. Geophys. Res., 106, 13,931-13,943.

Santer, B. D., T. M. L. Wigley, J. S. Boyle, D. J. Gaffen, J. J. Hnilo, D. Nychka, D. E. Parker, and K. E. Taylor (2000), Statistical significance of trends and trend differences in layer-average atmospheric temperature time series, J. Geophys. Res., 105, 7337-7356.

Schauer, U., H. Loeng, B. Rudels, V. K. Ozhigin, and W. Dieck (2002), Atlantic water flow through the Barents and Kara Seas, Deep Sea Res. Part I, 49, 2281-2298.

Schauer, U., E. Fahrbach, S. Østerhus, and G. Rohardt (2004), Arctic warming through Fram Strait: Oceanic heat transport from 3 years of measurements, J. Geophys. Res., 109, C06026, doi:10.1029/ 2003JC001823.

Schauer, U., A. Beszczynska-Möller, W. Walczowski, E. Fahrbach, J. Piechura, and E. Hansen (2008), Variation of measured heat flow through the Fram Strait between 1997 and 2006, in Arctic-Subarctic Ocean Fluxes: Defining the Role of the Northern Seas in Climate, edited by R. R. Dickson, J. Meincke, and P. Rhines, pp. 65-85, Springer, New York.

Schlichtholz, P. (2005), Climatological baroclinic forcing of the barotropic flow in the East Greenland Current in Fram Strait, J. Geophys. Res., 110, C08013, doi:10.1029/2004JC002701.

Schlichtholz, P., and I. Goszczko (2005), Was the Atlantic Water temperature in the West Spitsbergen Current predictable in the 1990s?, Geophys. Res. Lett., 32, L04610, doi:10.1029/2004GL021724.

Schlichtholz, P., and I. Goszczko (2006), Variability of the Atlantic water layer in the West Spitsbergen Current at $76.5^{\circ} \mathrm{N}$ in summer 1991-2003, Deep Sea Res. Part I, 53, 608-626.

Schlichtholz, P., and M.-N. Houssais (1999), An inverse modeling study in Fram Strait. Part II: water mass distribution and transports, Deep Sea Res. Part II, 46, 1137-1168.

Skagseth, Ø. (2008), Recirculation of Atlantic Water in the western Barents Sea, Geophys. Res. Lett., 35, L11606, doi:10.1029/2008GL033785.

Skagseth, Ø., T. Furevik, R. Ingvaldsen, H. Loeng, K. A. Mork, K. A. Orvik, and V. Ozhigin (2008), Volume and heat transports to the Arctic Ocean via the Norwegian and Barents seas, in Arctic-Subarctic Ocean Fluxes: Defining the Role of the Northern Seas in Climate, edited by R. R. Dickson, J. Meincke, and P. Rhines, pp. 45-64, Springer, New York. Sorteberg, A., and B. Kvingedal (2006), Atmospheric forcing on the Barents Sea winter ice extent, J. Clim., 19, 4772-4784.

Steele, M., R. Morley, and W. Ermold (2001), PHC: A global ocean hydrography with a high-quality Arctic Ocean, J. Clim., 14, 2079-2087. von Storch, H., and F. W. Zwiers (1999), Statistical Analysis in Climate Research, 484 pp., Cambridge Univ. Press, London.

Walczowski, W., and J. Piechura (2006), New evidence of warming propagating toward the Arctic Ocean, Geophys. Res. Lett., 33, L12601, doi:10.1029/2006GL025872.

M.-N. Houssais, LOCEAN, UMR 7159, CNRS/UPMC/IRD/MNHN, 4 place Jussieu, F-75252 Paris CEDEX 5, France.

P. Schlichtholz, Institute of Oceanology, Polish Academy of Sciences, Powstancow Warszawy 55, 81712 Sopot, Poland. (schlicht@iopan.gda.pl) 